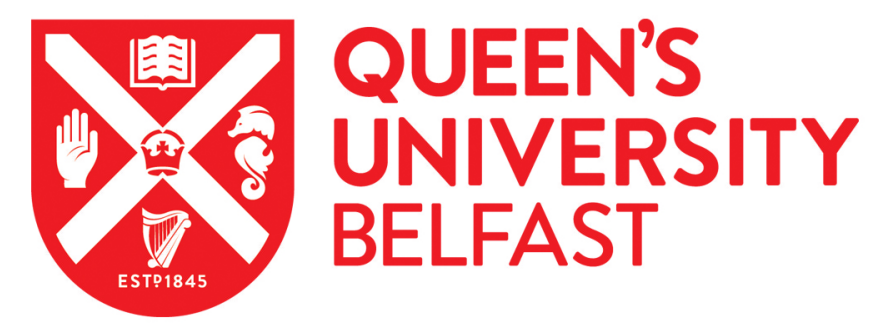

\title{
Simulation of failure in laminated polymer composites: Building-block validation
}

Furtado, C., Catalanotti, G., Arteiro, A., Gray, P. J., Wardle, B. L., \& Camanho, P. P. (2019). Simulation of failure in laminated polymer composites: Building-block validation. Composite Structures, 226, [111168].

https://doi.org/10.1016/j.compstruct.2019.111168

Published in:

Composite Structures

Document Version:

Peer reviewed version

Queen's University Belfast - Research Portal:

Link to publication record in Queen's University Belfast Research Portal

Publisher rights

Copyright 2019 Elsevier.

This manuscript is distributed under a Creative Commons Attribution-NonCommercial-NoDerivs License

(https://creativecommons.org/licenses/by-nc-nd/4.0/), which permits distribution and reproduction for non-commercial purposes, provided the author and source are cited.

\section{General rights}

Copyright for the publications made accessible via the Queen's University Belfast Research Portal is retained by the author(s) and / or other copyright owners and it is a condition of accessing these publications that users recognise and abide by the legal requirements associated with these rights.

Take down policy

The Research Portal is Queen's institutional repository that provides access to Queen's research output. Every effort has been made to ensure that content in the Research Portal does not infringe any person's rights, or applicable UK laws. If you discover content in the Research Portal that you believe breaches copyright or violates any law, please contact openaccess@qub.ac.uk. 


\section{Accepted Manuscript}

Simulation of failure in laminated polymer composites: building-block validation

C. Furtado, G. Catalanotti, A. Arteiro, P.J. Gray, B.L. Wardle, P.P. Camanho

PII: S0263-8223(19)31132-8

DOI: https://doi.org/10.1016/j.compstruct.2019.111168

Article Number: $\quad 111168$

Reference: COST 111168

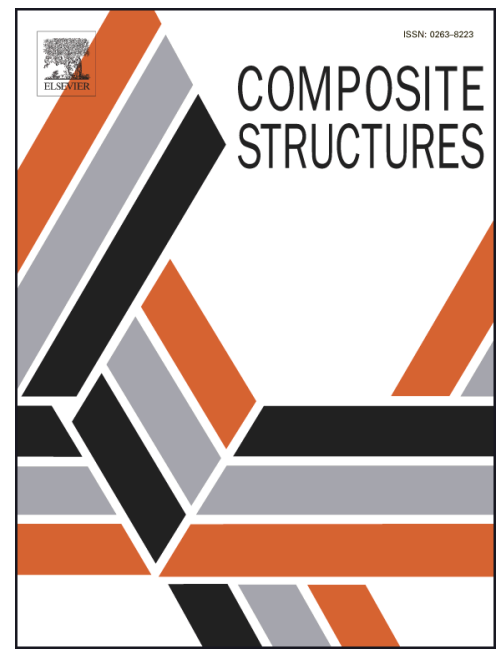

To appear in:

Composite Structures

Received Date:

1 April 2019

Revised Date:

4 June 2019

Accepted Date:

18 June 2019

Please cite this article as: Furtado, C., Catalanotti, G., Arteiro, A., Gray, P.J., Wardle, B.L., Camanho, P.P., Simulation of failure in laminated polymer composites: building-block validation, Composite Structures (2019), doi: https://doi.org/10.1016/j.compstruct.2019.111168

This is a PDF file of an unedited manuscript that has been accepted for publication. As a service to our customers we are providing this early version of the manuscript. The manuscript will undergo copyediting, typesetting, and review of the resulting proof before it is published in its final form. Please note that during the production process errors may be discovered which could affect the content, and all legal disclaimers that apply to the journal pertain. 


\title{
Simulation of failure in laminated polymer composites: building-block validation
}

\author{
C. Furtado ${ }^{\mathrm{a}, \mathrm{b}}$, G. Catalanotti ${ }^{\mathrm{c}}$, A. Arteiro ${ }^{\mathrm{a}, \mathrm{b}}$, P. J. Gray ${ }^{\mathrm{d}}$, B. L. Wardle ${ }^{\mathrm{e}}$, P.P. Camanho ${ }^{\mathrm{a}, \mathrm{b}, *}$ \\ ${ }^{a}$ DEMec, Faculdade de Engenharia, Universidade do Porto, Rua Dr. Roberto Frias, s/n, 4200-465 Porto, \\ Portugal \\ ${ }^{b}$ INEGI, Instituto de Ciência e Inovação em Engenharia Mecânica e Engenharia Industrial, Rua Dr. Roberto \\ Frias, 400, 4200-465 Porto, Portugal \\ ${ }^{c}$ Advanced Composites Research Group (ACRG), School of Mechanical and Aerospace Engineering, Queen's \\ University Belfast, Belfast BT9 5AH, UK \\ ${ }^{d}$ AIRBUS Operations GmbH, Kreetslag 10, 21129 Hamburg, Germany \\ ${ }^{e}$ Department of Aeronautics and Astronautics, Massachusetts Institute of Technology, 77 Massachusetts \\ Avenue, Cambridge, MA 02139, United States
}

\begin{abstract}
The development of numerical tools to complement the experimental determination of structural design parameters is of key importance to hasten the certification process of new materials and structures. In this work, a methodology to simulate elastic and inelastic deformation of composite laminates at the subcomponent level based on finite element analysis is proposed. A modified version of a continuum damage model proposed in the literature combined with a frictional cohesive zone model is used to capture the intralaminar and interlaminar damage and failure of composite laminates in general loading conditions. The methodology is validated for three aerospace-grade carbon fibre reinforced (epoxy) polymer composite material systems and coupon configurations with increasing level of complexity, including unnotched tension/compression, open-hole tension/compression and filled hole compression. The predictions obtained are in good agreement with the experimental results for all the test cases, oftentimes within standard error of the tests, with maximum relative error of $13 \%$.
\end{abstract}

Keywords: A. Composite laminates, B. Continuum damage mechanics, C. Finite element analysis

\footnotetext{
*Corresponding author. Tel.: +351 220414049.

Email address: pcamanho@fe.up.pt (P.P. Camanho)
} 


\section{Introduction}

The design of composite structures is based on testing and simulation of composite coupons that represent structural details under simple loading scenarios, following an approach known as the building block approach [1]. This process ensures that a deep understanding of the structural behaviour under simple loading conditions is gained at the early stages of the design process, consequently mitigating the risk associated with the design of complex structures that usually have strict certification and safety requirements. The experimental determination of these design parameters is an inherently costly and time-consuming process, and consequently delays both the introduction of new materials and the design of new structures, two aspects that are critical for the competitiveness of the aeronautical industry. The development of numerical models to complement, or potentially replace, the purely experimental determination of the design parameters is, therefore, of key importance. Numerical solutions based on analytical [2-8] and finite elements models at the meso and macro scale [9-21] have been proposed; however, their use is still not widespread since the models are generally not implemented in commercially available software and/or their validation has not gained widespread acceptance for material systems of interest.

Finite element models to simulate failure of composite laminates using the ply as a building block have been proposed by several authors $[9-20]$. These are particularly powerful solutions given their flexibility to estimate the material behaviour of different laminates, geometries and loading conditions. However, their efficient use relies not only on the accuracy of the predictions of the ultimate failure loads, but also on the time frame in which these predictions are obtained. The time required to run the numerical models should be compatible with the requirements from industry. Moreover, it is important that the models rely on physically based material properties that can be determined following well-defined test methods and rely as little as possible on numerical calibration.

The objective of this work is to develop and implement a methodology to simulate composite laminates at coupon level compatible with industrial requirements. The model should be able to predict the strength of different structural details without changing its formulations or required material properties. The model is based on the continuum damage model proposed by Maimí et al. [16-18] and the cohesive zone model proposed by Turon et al. [22] and Alfano et al. [23]. The models were modified (as described in later sections) from their original versions to improve their ability to accurately predict damage initiation and evolution under general loading conditions 
while maintaining the model complexity and, therefore, the computational cost. The current work serves as basis for modelling more complex geometries [24-26] and can potentially be used for the generation of statistically based design allowables for the most simple test cases when allied with powerful statistical tools.

\section{Modelling strategy}

The modelling strategy proposed in this work is presented in the following sections. The continuum damage model for the ply and respective improvements proposed are detailed in section 2.1 and the cohesive zone model for the interface used here is presented in section 2.2.

\subsection{Continuum damage model for the ply}

Maimí et al. [16-18] proposed a continuum damage model to predict the onset and accumulation of intralaminar damage mechanisms in laminated composites. Generally speaking, the formulation of the continuum damage model starts by the definition of a potential (the complementary free energy density) as a function of damage variables associated to the different failure modes. It is also necessary to define the damage activation functions, i.e. the conditions that lead to the onset of inelastic response, and the damage evolution functions. The model was developed assuming that the out-of-plane stresses are too small to promote damage and, therefore, damage is activated only by the in-plane components of the stress tensor. This assumption is not suitable for test cases where the triaxiality of the stresses is not negligible. In this work, the model was modified to improve its ability to accurately predict damage initiation and evolution under general load conditions without increasing the model complexity and, therefore, the computational cost. These modifications are reported in the following sections, with full details of the original model are available in Refs. [16-18].

\subsubsection{Constitutive model}

The scalar function corresponding to the ply complementary free energy density, accounting for the different longitudinal Young's moduli in tension and compression reads:

$$
\begin{array}{r}
\mathcal{G}=\frac{\left\langle\sigma_{11}\right\rangle^{2}}{2\left(1-d_{1}\right) E_{1}}+\frac{\left\langle-\sigma_{11}\right\rangle^{2}}{2\left(1-d_{1}\right) E_{1 c}}-\nu_{12} \sigma_{22}\left(\frac{\left\langle\sigma_{11}\right\rangle}{E_{1}}+\frac{\left\langle-\sigma_{11}\right\rangle}{E_{1 c}}\right)+ \\
+\frac{\sigma_{22}^{2}}{2\left(1-d_{2}\right) E_{2}}+\frac{\sigma_{12}^{2}}{2\left(1-d_{6}\right) G_{12}}+\left(\alpha_{11} \sigma_{11}+\alpha_{22} \sigma_{22}\right) \Delta T+\left(\beta_{11} \sigma_{11}+\beta_{22} \sigma_{22}\right) \Delta M
\end{array}
$$




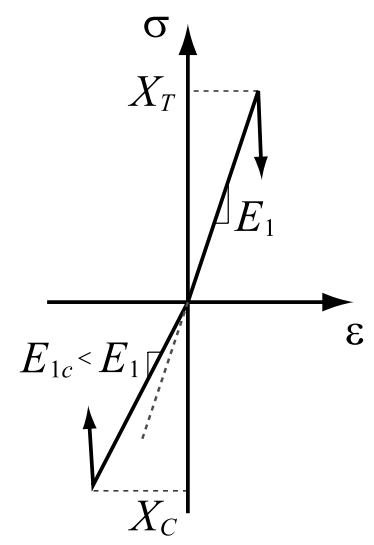

Figure 1: Longitudinal nonlinear ply behaviour in tension and compression.

where $\sigma_{i j}(i, j=1,2)$ are the stress components, $d_{i}(i=1,2,6)$ are the scalar damage variables, $E_{1}$ and $E_{1 c}$ are respectively the longitudinal tensile and compressive Young's moduli, $E_{2}$ is the transverse Young's modulus, $G_{12}$ is the shear modulus, $\nu_{12}$ is the Poisson's ratio, $\alpha_{i i}(i=1,2)$ are the coefficients of thermal expansion, $\beta_{i i}(i=1,2)$ are the coefficients of hygroscopic expansion, $\Delta T$ is the temperature variation, $\Delta M$ is the variation in moisture content, and $\langle\bullet\rangle$ stands for the Macaulay brackets, which return the argument $\bullet$ if positive, and zero otherwise. The previous equation results in a non-linear behaviour in tension and compression if $E_{1} \neq E_{1 c}$ - see Fig. 1.

The strain tensor reads:

$$
\epsilon=\frac{\partial \mathcal{G}}{\partial \sigma}=\mathbf{H}: \sigma+\alpha \Delta T+\beta \Delta M
$$

where $\mathbf{H}$ is the lamina compliance tensor:

$$
\mathbf{H}=\frac{\partial^{2} \mathcal{G}}{\partial \sigma^{2}}=\left[\begin{array}{ccc}
\frac{1}{\left(1-d_{1}\right)\left|\sigma_{11}\right|}\left(\frac{\left\langle\sigma_{11}\right\rangle}{E_{1}}+\frac{\left\langle-\sigma_{11}\right\rangle}{E_{1 c}}\right) & -\frac{\nu_{12}}{\left|\sigma_{11}\right|}\left(\frac{\left\langle\sigma_{11}\right\rangle}{E_{1}}+\frac{\left\langle-\sigma_{11}\right\rangle}{E_{1 c}}\right) & 0 \\
-\frac{\nu_{12}}{\left|\sigma_{11}\right|}\left(\frac{\left\langle\sigma_{11}\right\rangle}{E_{1}}+\frac{\left\langle-\sigma_{11}\right\rangle}{E_{1 c}}\right) & \frac{1}{\left(1-d_{2}\right) E_{2}} & 0 \\
0 & 0 & \frac{1}{\left(1-d_{6}\right) G_{12}}
\end{array}\right]
$$

To account for closure of longitudinal and transverse cracks under load reversal, four damage variables associated with longitudinal $\left(d_{1+}\right.$ and $\left.d_{1-}\right)$ and transverse $\left(d_{2+}\right.$ and $\left.d_{2-}\right)$ damage are considered to define the $d_{1}$ and $d_{2}$ :

$$
d_{1}=d_{1+} \frac{\left\langle\sigma_{11}\right\rangle}{\left|\sigma_{11}\right|}+d_{1-} \frac{\left\langle-\sigma_{11}\right\rangle}{\left|\sigma_{11}\right|}
$$




$$
d_{2}=d_{2+} \frac{\left\langle\sigma_{22}\right\rangle}{\left|\sigma_{22}\right|}+d_{2-} \frac{\left\langle-\sigma_{22}\right\rangle}{\left|\sigma_{22}\right|}
$$

Since shear damage represents transverse cracks which do not close under shear stresses, only one variable is considered for shear damage $\left(d_{6}\right)$.

\subsubsection{Damage activation functions}

The continuum damage model predicts four intralaminar failure mechanisms: longitudinal tensile failure $\left(F_{1+}\right)$, longitudinal compressive failure $\left(F_{1-}\right)$, transverse failure where the crack plane is perpendicular to the mid-plane of the laminate $\left(F_{2+}\right)$, and transverse failure where the crack plane is not perpendicular to the mid-plane of the laminate $\left(F_{2-}\right)$ [17]. The respective activation functions are defined as:

$$
\begin{array}{ll}
F_{1+}=\phi_{1+}-r_{1+} \leq 0 \quad ; \quad F_{1-}=\phi_{1-}-r_{1-} \leq 0 \\
F_{2+}=\phi_{2+}-r_{2+} \leq 0 \quad ; \quad F_{2-}=\phi_{2-}-r_{2-} \leq 0
\end{array}
$$

The four loading functions, $\phi_{i}(i=1+, 1-, 2+, 2-)$, define the failure surfaces, and are established in terms of strain tensor, using an approximation of the LaRC03-04 failure criteria [27] that will be discussed later in section 2.1.4.1. For the sake of completeness, the loading functions are reported below but the reader is referred to Refs. [16-18] for full details on their definition and their physical meaning. The material properties of the ply are defined in Appendix A. The loading functions read:

$$
\begin{aligned}
& \phi_{1+}=\frac{E_{1}}{X_{T}} \varepsilon_{11} \\
& \phi_{2+}=\left\{\begin{array}{ccc}
\sqrt{\left(1-\frac{\mathcal{G}_{2+}}{\mathcal{G}_{6}}\right) \frac{\tilde{\sigma}_{22}}{Y_{T}}+\left(\frac{\mathcal{G}_{2+}}{\mathcal{G}_{6}}\right)\left(\frac{\tilde{\sigma}_{22}}{Y_{T}}\right)^{2}+\left(\frac{\tilde{\sigma}_{12}}{S_{L}}\right)^{2}} & \text { if } & \tilde{\sigma}_{22} \geq 0 \\
\frac{1}{S_{L}}\left\langle\left|\tilde{\sigma}_{12}\right|+\eta^{L} \tilde{\sigma}_{22}\right\rangle & \text { if } & \tilde{\sigma}_{22}<0
\end{array}\right. \\
& \phi_{1-}=\frac{\left\langle\left|\tilde{\sigma}_{12}^{R}\right|+\eta^{L} \tilde{\sigma}_{22}^{R}\right\rangle}{S_{L}} \\
& \phi_{2-}=\sqrt{\left(\frac{\tilde{\tau}_{\text {eff }}^{T}}{S_{T}}\right)^{2}+\left(\frac{\tilde{\tau}_{\text {eff }}^{L}}{S_{L}}\right)^{2}} \quad \text { if } \quad \tilde{\sigma}_{22}<0
\end{aligned}
$$

The effective (undamaged) stress tensor, $\tilde{\boldsymbol{\sigma}}$, is a function of the undamaged stiffness tensor, $\mathbf{C}_{\mathbf{0}}$, and of the elastic strains $\varepsilon_{e}$ :

$$
\tilde{\boldsymbol{\sigma}}=\mathbf{C}_{0} \boldsymbol{\varepsilon}_{e}
$$


The components of the effective stress tensor in the coordinate system associated with the rotation of the fibres are calculated as:

$$
\begin{aligned}
& \tilde{\sigma}_{22}^{R}=\tilde{\sigma}_{11} \sin ^{2} \varphi^{C}+\tilde{\sigma}_{22} \cos ^{2} \varphi^{C}-2\left|\tilde{\sigma}_{12}\right| \sin \varphi^{C} \cos \varphi^{C} \\
& \tilde{\sigma}_{12}^{R}=\left(\tilde{\sigma}_{22}-\tilde{\sigma}_{11}\right) \sin \varphi^{C} \cos \varphi^{C}+\left|\tilde{\sigma}_{12}\right|\left(\cos ^{2} \varphi^{C}-\sin ^{2} \varphi^{C}\right)
\end{aligned}
$$

where the misaligned angle at failure of a UD ply subjected to uniaxial longitudinal compression, $\varphi^{C}$, is given by:

$$
\varphi^{C}=\arctan \left(\frac{1-\sqrt{1-4\left(S_{L} / X_{C}+\eta^{L}\right) S_{L} / X_{C}}}{2\left(S_{L} / X_{C}+\eta^{L}\right)}\right)
$$

The effective shear strengths, $\tilde{\tau}_{\text {eff }}^{T}$ and $\tilde{\tau}_{\text {eff }}^{L}$ are given by:

$$
\begin{aligned}
& \tilde{\tau}_{\text {eff }}^{T}=\left\langle-\tilde{\sigma}_{22} \cos \left(\alpha_{0}\right)\left(\sin \left(\alpha_{0}\right)-\eta^{T} \cos \left(\alpha_{0}\right) \cos (\theta)\right)\right\rangle \\
& \tilde{\tau}_{\text {eff }}^{L}=\left\langle\cos \left(\alpha_{0}\right)\left(\left|\tilde{\sigma}_{12}\right|+\eta^{L} \tilde{\sigma}_{22} \cos \left(\alpha_{0}\right) \sin (\theta)\right)\right\rangle
\end{aligned}
$$

where the longitudinal and transverse frictional coefficients, $\eta^{L}$ and $\eta^{T}$, respectively, read:

$$
\eta^{L} \approx-\frac{S_{L} \cos \left(2 \alpha_{0}\right)}{Y_{C} \cos ^{2} \alpha_{0}} \quad ; \quad \eta^{T}=-\frac{1}{\tan \left(2 \alpha_{0}\right)}
$$

the transverse shear strength, $S_{T}$ is approximated by:

$$
S_{T}=Y_{C} \cos \left(\alpha_{0}\right)\left[\sin \left(\alpha_{0}\right)+\frac{\cos \left(\alpha_{0}\right)}{\tan \left(2 \alpha_{0}\right)}\right]
$$

and the sliding angle, $\theta$ is given by:

$$
\theta=\arctan \left(\frac{-\left|\tilde{\sigma}_{12}\right|}{\tilde{\sigma}_{22} \sin \left(\alpha_{0}\right)}\right)
$$

The elastic domain thresholds, $r_{i}(i=1+, 1-, 2+, 2-)$ are related to the damage variables by the damage evolution laws. $r_{i}$ take the initial value 1 when the material is undamaged and increase as damage evolves. The elastic domain thresholds read:

$$
\begin{aligned}
& r_{1+}=\max \left\{1, \max _{s=0, t}\left\{\phi_{1+}^{s}\right\}, \max _{s=0, t}\left\{\phi_{1-}^{s}\right\}\right\} \\
& r_{1-}=\max \left\{1, \max _{s=0, t}\left\{\phi_{1-}^{s}\right\}\right\} \\
& r_{2+}=\max \left\{1, \max _{s=0, t}\left\{\phi_{2+}^{s}\right\}, \max _{s=0, t}\left\{\phi_{2-}^{s}\right\}\right\} \\
& r_{2-}=\max \left\{1, \max _{s=0, t}\left\{\phi_{2-}^{s}\right\}\right\}
\end{aligned}
$$




\subsubsection{Uniaxial response}

To accurately capture the mechanical response of a unidirectional (UD) composite lamina before and after initiation of the different failure modes, a different stress-strain response is considered for each damage mechanism (Fig. 2):

- Under longitudinal tensile loading, a linear-elastic response followed by a bi-linear softening law after longitudinal tensile damage initiation is assumed - Fig. 2A.

- Following the experimental findings of Moran et al. [28], under longitudinal compressive loading the initially linear-elastic response (preceding kink band formation) is followed by linear softening, corresponding to the propagation of a kink band, until reaching a plateau, corresponding to kink band broadening at constant stress - Fig. 2B.

- The transverse tensile and compressive stress-strain relations are represented by a linear softening law following an initially linear-elastic response - Fig. 2C.

- Finally, under in-plane shear, a nonlinear elasto-plastic response is assumed, represented by a reduced slope in the stress-strain curve to account for the inelastic response caused by plastic deformation, followed by a linear softening law - Fig. 2D.

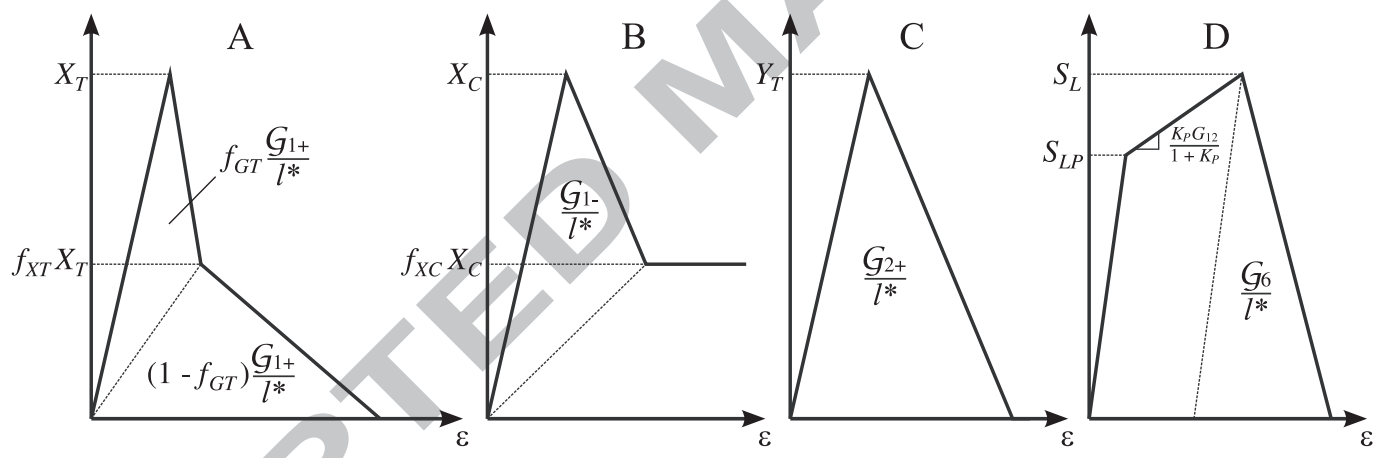

Figure 2: Uniaxial response in A) longitudinal tension, B) longitudinal compression, C) transverse tension or compression and D) in-plane shear.

To ensure correct energy dissipation during damage propagation and to avoid mesh-size dependency of the numerical solution, the slopes of the softening laws are determined as a function of the fracture toughness $\mathcal{G}_{c}$ associated with each failure mechanism $\left(\mathcal{G}_{1+}, \mathcal{G}_{1-}, \mathcal{G}_{2+} / \mathcal{G}_{2-}\right.$, and $\mathcal{G}_{6}$ - see Fig. 2), and as a function of the characteristic length $l^{*}$ of the finite elements [29]. Since quadrangular elements are used, a damage mode independent element characteristic length is defined. 


\subsubsection{Effect of though-the-thickness stress}

The three modifications related to the effect of pressure on damage onset and propagation proposed in this work are reported hereafter. A damage activation function for longitudinal compression that accounts for the effect of though-thickness stresses based on the 3D failure criteria proposed by Camanho et al. [30] is proposed in section 2.1.4.1 and engineering solutions to account for ii) the effect of pressure on the longitudinal compression and iii) in-plane shear fracture toughness are proposed in sections 2.1.4.2 and 2.1.4.3, respectively.

\subsubsection{Damage activation function for longitudinal compression}

The model proposed in Refs. [16-18] assumed that the out-of-plane stress components are negligibly small to promote damage, and therefore only the in-plane stress components of the stress tensor activate damage. However, this assumption is not suitable for test cases where the triaxiality of the stress state is not negligible. Therefore, to improve the ability to accurately predict damage initiation and evolution in 3D test cases, the model initially proposed in Refs. [16-18] was modified to include a 3D invariant-based failure criterion for fibre kinking (Fig. 3) [30]. This failure criterion is used to define an artificial in-plane shear strength $S_{L}^{e f}$ (see Fig. 4), which represents the effect of hydrostatic pressure on the shear response of the polymer matrix [31-33]. $S_{L}^{e f}$ is determined imposing that, at failure, the 2D damage activation function [17] is equal to the activation function from the $3 \mathrm{D}$ invariant-based failure criterion [30]:

$$
\frac{\left\langle\left|\tilde{\sigma}_{12}^{R}\right|+\eta^{L} \tilde{\sigma}_{22}^{R}\right\rangle}{S_{L}}=\alpha_{1} I_{1}+\alpha_{2} I_{2}+\alpha_{3} I_{3}+\alpha_{32} I_{3}^{2}
$$

and solving for the in-plane shear strength, $S_{L}$. The $2 \mathrm{D}$ damage activation function (left-hand side of Eq. (16)), is defined in section 2.1.2. The 3D invariant-based failure criterion for fibre kinking (right-hand side of Eq. (16)) is defined by the set of invariants:

$$
\begin{aligned}
I_{1} & =\frac{1}{2} \operatorname{tr}\left(\tilde{\boldsymbol{\sigma}}^{p}\right)^{2}-\mathbf{a}\left(\tilde{\boldsymbol{\sigma}}^{p}\right)^{2} \mathbf{a} \\
I_{2} & =\mathbf{a}\left(\tilde{\boldsymbol{\sigma}}^{p}\right)^{2} \mathbf{a} \\
I_{3} & =\operatorname{tr} \tilde{\boldsymbol{\sigma}}-\mathbf{a} \tilde{\boldsymbol{\sigma}} \mathbf{a}
\end{aligned}
$$

assuming a decomposition of the effective stress tensor $\tilde{\boldsymbol{\sigma}}$ in plasticity inducing stresses $\tilde{\boldsymbol{\sigma}}^{p}$ and reaction stresses $\tilde{\boldsymbol{\sigma}}^{r}$ : 

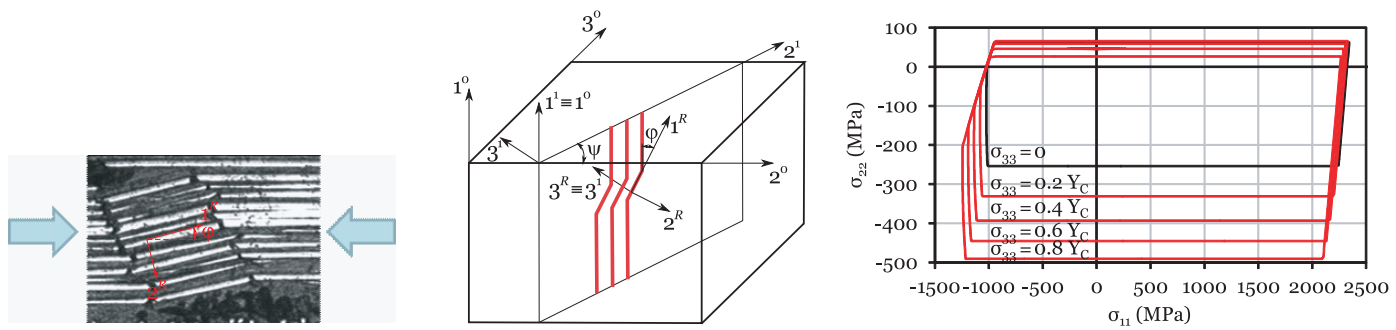

Figure 3: Fibre kinking kinematics and effect of through-thickness stresses predicted by a 3D invariant-based failure criterion [30].

$$
\begin{aligned}
& \tilde{\boldsymbol{\sigma}}^{p}=\tilde{\boldsymbol{\sigma}}-\tilde{\boldsymbol{\sigma}}^{r} \\
& \tilde{\boldsymbol{\sigma}}^{r}=\frac{1}{2}(\operatorname{tr} \tilde{\boldsymbol{\sigma}}-\mathbf{a} \tilde{\boldsymbol{\sigma}} \mathbf{a}) \mathbf{1}-\frac{1}{2}(\operatorname{tr} \tilde{\boldsymbol{\sigma}}-3 \mathbf{a} \tilde{\boldsymbol{\sigma}} \mathbf{a}) \mathbf{A}
\end{aligned}
$$

where $\mathbf{1}$ is the identity tensor and $\mathbf{A}=\mathbf{a} \otimes \mathbf{a}$ is the structural tensor that represents the intrinsic characteristic direction of the transversely isotropic material. The preferred direction $\mathbf{a}$, in the case of UD fibre-reinforced composites, coincides with the fibre direction. For the rotated fibres in the misalignment frame of a kink band, this preferred direction reads [30]:

$$
\mathbf{a}=\left[\begin{array}{c}
\cos \varphi \\
\cos \psi \sin \varphi \\
\sin \psi \sin \varphi
\end{array}\right]
$$

where $\varphi$ is the misalignment angle and $\psi$ is the angle of the kinking plane (see Fig. 3). The parameters $\alpha_{i}$ (with $i=1,2,3,32$ ) are simple functions of the transverse and shear ply strengths that depend on the direction of the applied normal load through the sign of $I_{3}$ to account for the tensile/compressive strengths asymmetry (for more details, the reader is referred to Ref. [30]).

\subsubsection{Softening law for longitudinal compression}

In this work, the 3D invariant-based failure criterion for fibre kinking included in the damage model is also used to scale the fracture toughness for longitudinal compression $\left(\mathcal{G}_{1-}\right)$ and the longitudinal compressive strength ratio at the inflection point $\left(f_{X C}\right)$ as a function of the applied pressure (Fig. 5). The fracture toughness is scaled proportionally to the increase of longitudinal compressive strength: 


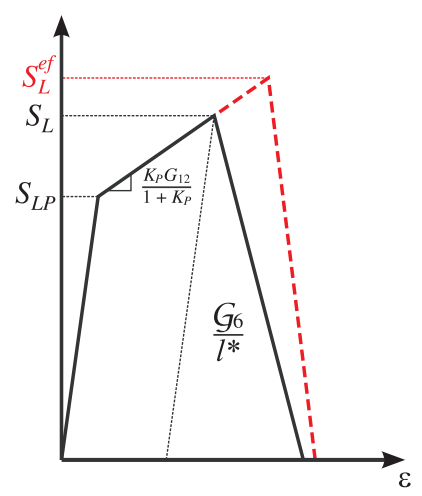

Figure 4: Effect of hydrostatic pressure on the longitudinal in-plane shear response.

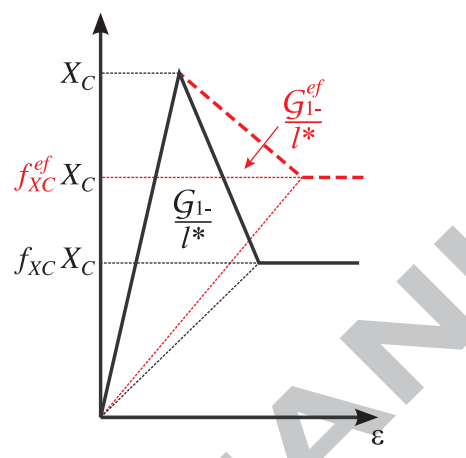

Figure 5: Effect of hydrostatic pressure on the longitudinal compressive response.

$$
\mathcal{G}_{1-}^{e f}=\mathcal{G}_{1}-\left|\frac{\bar{\sigma}_{11}}{X_{C}}\right|, \quad \text { if } \quad\left|\frac{\bar{\sigma}_{11}}{X_{C}}\right|>1
$$

where $X_{C}$ is the uniaxial longitudinal compressive strength and $\bar{\sigma}_{11}$ is the compressive strength predicted by the 3D invariant-based failure criterion for multiaxial stress states (see Fig. 6). The effective longitudinal compressive strength ratio at the inflection point $\left(f_{X C}^{e f}\right)$ is:

$$
f_{X C}^{e f}=\min \left\{1, f_{X C}\left(1-f_{f x c}\left\langle-I_{3}\right\rangle\right)\right\}
$$

where $I_{3}=\sigma_{22}+\sigma_{33}$ is the third invariant of the 3D invariant-based failure criterion [30] and $f_{f x c}$ is a frictional parameter that needs to be calibrated using the experimental curves from a bearing, filled-hole compression or open-hole compression test. 


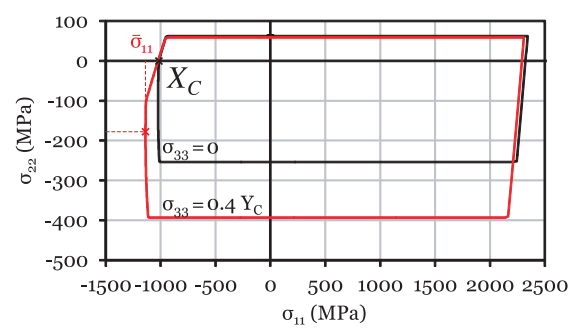

Figure 6: UD ply failure by fibre kinking under multiaxial stress states.
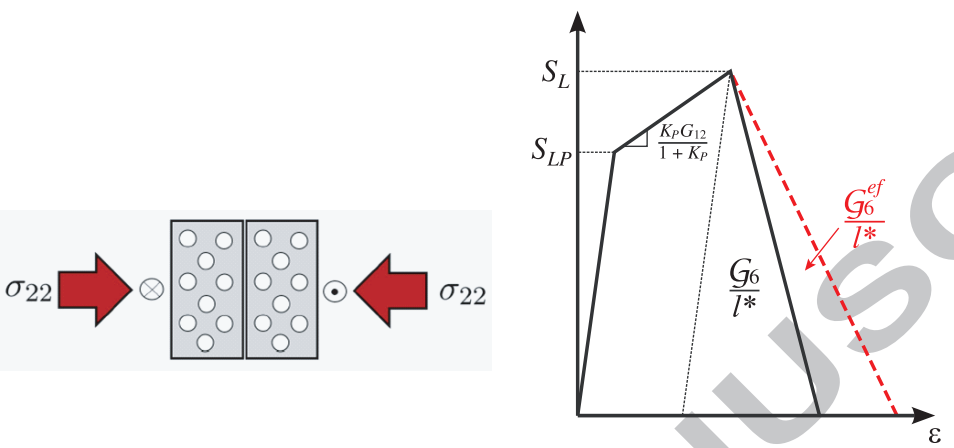

Figure 7: Effect of transverse compressive stresses on the longitudinal in-plane shear response.

\subsubsection{Fracture toughness for in-plane shear}

It has been shown experimentally that through-thickness compression increases the apparent interlaminar mode II fracture toughness and delays delamination onset [34-36]. Cui et al. [37] suggested that this strengthening effect can be represented by an effective fracture toughness, $G_{I I c}^{e f}$ :

$$
G_{I I c}^{e f}=G_{I I c}\left(1-\eta_{G}\left\langle-\sigma_{33}\right\rangle\right)
$$

where $G_{I I c}$ is the mode II fracture toughness, $\eta_{G}$ is a material dependent empirically derived enhancement factor, $\sigma_{33}$ is the through-thickness stress and $\langle x\rangle$ is the Macaulay operator [37, 38]. It can be postulated that, at the ply level, applying transverse compression stress should have a similar strengthening effect since a similar fracture process occurs for transverse cracking and, therefore, the effective fracture toughness for in-plane shear can be expressed as:

$$
\mathcal{G}_{6}^{e f}=\mathcal{G}_{6}\left(1-\eta_{G}\left\langle-\sigma_{22}\right\rangle\right)
$$

The resulting effect of this modification is shown in Fig. 7 . 


\subsubsection{In-situ strengths}

It is clear that a proper model formulation is fundamental to accurately predict damage onset and propagation in composite laminates, however the material properties used to populate the model also have to be accurately determined. It is particularly important to take into account that some of the ply strengths are in-situ properties, i.e. are a function of the ply thickness in a multidirectional laminate. This effect was first detected experimentally for transverse tension and in-plane shear by Parvizi et al. [39], and further analysed by other authors [40-49]. Camanho et al. [48] proposed an analytical model to predict the in-situ transverse tension, $Y_{T}^{i s}$, and in-plane shear, $S_{L}^{i s}$, strengths using Fracture Mechanics models that relate the in-situ properties with the fracture toughness of the material.

The calculation of the in-situ shear strength relies on the approximation of the non-linear shear response. The shear response is usually approximated by either the Tsai-Hahn or the Ramberg-Osgood laws. Different approximations result in different predictions of the in-situ strengths since, as currently derived, they are highly dependent on the shape of the stress-strain behaviour prior to failure and, therefore, highly dependent on the law used to approximate the shear response [50]. Given the high dependence of the in-situ shear strengths on the shear response law, adopting contradictory assumptions for the shear behaviour to derive the in-situ strengths and to the material constitutive model should be avoided [50]. To maintain consistency, the in-situ strengths should, therefore, be derived assuming the bilinear shear response implemented in the model and shown in Fig. 2.D. The derivation of the in-situ strengths was carried out and implemented during this work, and are presented in Appendix B. These properties are used in the failure criteria.

\subsection{Cohesive zone model for the interfaces between plies}

Accurate simulation of failure of composite laminates requires not only the prediction of intralaminar damage, but also the prediction of delamination onset and propagation. In the framework of this work, some common problems regarding the prediction of delamination were identified. Firstly, most of the formulations are developed for pure mode I and II loading and then extended for mixed-mode loading and are, therefore, poorly validated for mixed mode loading conditions. Secondly, in the formulation of cohesive zone models, friction is usually not accounted for. The effect of these issues can be minimized by using engineering solutions proposed by several authors $[37,38,51,52]$; however a rigorous cohesive zone model to simulate 
delamination under mixed mode loading and that accounts for the effect of friction is adopted here. Based on their previous work [51], Turon et al. [22] recently proposed a cohesive zone model that accurately predicts damage propagation under mixed mode loading by including a mode-dependent penalty stiffness. Alfano et al. [23] proposed an approach to combine interface damage with friction considering linear elastic behaviour for the undamaged part and the damage evolution law proposed by Crisfield et al. [53] combined with a simple Coulomb friction law. However, any cohesive zone model and friction law can be used. The cohesive zone model proposed by Turon et al. [22] was combined with the Coulomb friction law by the authors [36] and is used in this work to simulate delamination onset and propagation.

\subsubsection{Constitutive model}

Alfano et al. [23] proposed that the homogenized interface stress over the representative element area, $\tau$, is given by:

$$
\tau=(1-d)\left[\begin{array}{ccc}
K_{s h} & 0 & 0 \\
0 & K_{s h} & 0 \\
0 & 0 & K_{n}
\end{array}\right]\left[\begin{array}{c}
\Delta_{1} \\
\Delta_{2} \\
\Delta_{n}
\end{array}\right]+d\left[\begin{array}{ccc}
K_{s h} & 0 & 0 \\
0 & K_{s h} & 0 \\
0 & 0 & K_{n}
\end{array}\right]\left[\begin{array}{l}
\Delta_{1}-\Delta_{1}^{d i} \\
\Delta_{2}-\Delta_{2}^{d i} \\
-\left\langle-\Delta_{n}\right\rangle
\end{array}\right]
$$

where $d$ is the damage variable, $\mathbf{K}$ is the stiffness matrix, $\Delta$ is the relative displacement vector and $\boldsymbol{\Delta}^{\mathbf{d i}}$ is the inelastic sliding displacement. The following friction function was introduced:

$$
\phi=\mu \tau_{n}^{d}+\tau_{s h}^{d}
$$

where $\tau_{s h}^{d}$ is given by

$$
\tau_{s h}^{d}=\sqrt{\left(\tau_{1}^{d}\right)^{2}+\left(\tau_{2}^{d}\right)^{2}}
$$

The evolution of $\Delta^{\mathrm{di}}$ is assumed to be governed by the following nonassociative relationship:

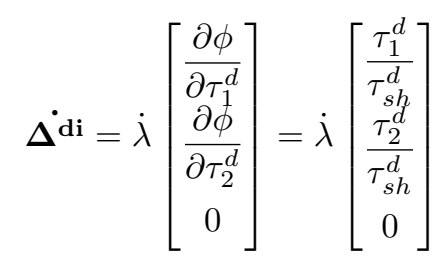

with the Kuhn-Tucker conditions $\dot{\lambda} \geq 0, \phi(\tau) \leq 0$ and $\dot{\lambda} \phi(\tau)=0$.

\subsubsection{Mode dependent penalty stiffness}

Most of the formulations are developed for pure mode loading and then extended for mixedmode loading and are, therefore, poorly validated for mixed mode loading conditions. Turon et al. 
[52] concluded that, to avoid erroneous calculation of the energy dissipation during mixed mode loading and to guarantee accurate prediction of damage propagation under mixed mode loading conditions, the relationship between the normal and shear interface stiffness $\left(K_{n}\right.$ and $\left.K_{s h}\right)$, the mode I and mode II fracture toughness $\left(\mathcal{G}_{I c}\right.$ and $\left.\mathcal{G}_{I c}\right)$ and the normal and shear interlaminar strengths $\left(\tau_{n}^{0}\right.$ and $\left.\tau_{s h}^{0}\right)$ should be given as:

$$
\frac{K_{s h}}{K_{n}}=\frac{\mathcal{G}_{I c}}{\mathcal{G}_{I I c}}\left(\frac{\tau_{s h}^{0}}{\tau_{n}^{0}}\right)^{2}
$$

In their previous work, Turon et al. [52] assumed that the shear and normal penalty stiffness were equal $K_{n}=K_{s h}$ and therefore, the relation was imposed considering that the shear strength should not be a fully independent material property but instead a function of the fracture toughness and the normal strength:

$$
\tau_{s h}^{0}=\tau_{n}^{0} \sqrt{\frac{\mathcal{G}_{I I c}}{\mathcal{G}_{I c}}}
$$

Note that the interface stiffness $\left(K_{n}\right.$ and $\left.K_{s h}\right)$ are parameters that ensure a stiff connection between the crack surfaces before crack propagation, but the fracture toughness $\left(\mathcal{G}_{\text {Ic }}\right.$ and $\left.\mathcal{G}_{\text {IIc }}\right)$ and the interlaminar strengths $\left(\tau_{n}^{0}\right.$ and $\left.\tau_{s h}^{0}\right)$ are properties that can be measured experimentally. For this reason, Turon et al. [22] reformulated the model assuming a dependent interface stiffness, $K_{n} \neq K_{s h}$, instead of dependent shear strength, $\tau_{s h}^{0}=f\left(\tau_{n}^{0}, \mathcal{G}_{I I c}, \mathcal{G}_{I I c}\right)$ :

$$
K_{s h}=K_{n} \frac{\mathcal{G}_{I c}}{\mathcal{G}_{I I c}}\left(\frac{\tau_{s h}^{0}}{\tau_{n}^{0}}\right)^{2}
$$

This engineering solution required the reformulation of the cohesive zone model to include the mode-dependent penalty stiffness.

To formulate the damage evolution law, the mixed-mode norms of the tractions, $\tau$ and the displacement jumps $\lambda$ have to be defined. Following Refs. [54, 55], Turon et al. [22] defined the mixed-mode traction as a function of the Euclidean norm of the individual tractions along the 1, 2 and 3 directions accounting for different penalty stiffness. Under these assumptions, the mixed-mode norm of the displacement jump is redefined as:

$$
\lambda=\frac{K_{s h} \Delta_{s h}^{2}+K_{n} \Delta_{n}^{2}-K_{n}\left\langle-\Delta_{n}\right\rangle^{2}}{\sqrt{K_{s h}^{2} \Delta_{s h}^{2}+K_{n}^{2} \Delta_{n}^{2}-K_{n}^{2}\left\langle-\Delta_{n}\right\rangle^{2}}}
$$

\subsubsection{Damage evolution law}

The damage activation function is given by [22]:

$$
F(\Delta)=H(\Delta)-r_{d} \leq 0
$$


where $H(\Delta)$ is a monotonic loading function, and $r_{d}$ is the threshold function given, respectively, by:

$$
\begin{gathered}
H(\Delta)=\min \left(\frac{\lambda-\Delta^{o}}{\Delta^{f}-\Delta^{o}}, 1\right) \\
r_{d}=\max \left(1, \max _{\mathrm{s}}[H(\Delta)]\right) \quad 0<s<t \quad \forall t
\end{gathered}
$$

being $\Delta^{o}$ and $\Delta^{f}$ the displacement jumps corresponding to delamination onset and propagation under mixed-mode conditions, respectively. The Benzeggagh and Kennane criterion [56] is used to define these parameters:

$$
\begin{aligned}
& \Delta^{o}=\sqrt{\frac{K_{n}\left(\Delta_{n}^{o}\right)^{2}+\left[K_{s h}\left(\Delta_{s h}^{o}\right)^{2}-K_{n}\left(\Delta_{n}^{o}\right)^{2}\right] \beta^{\eta}}{K_{\beta}}} \\
& \Delta^{f}=\frac{K_{n} \Delta_{n}^{o} \Delta_{n}^{f}+\left[K_{s h} \Delta_{s h}^{o} \Delta_{s h}^{f}-K_{n} \Delta_{n}^{o} \Delta_{n}^{f}\right] \beta^{\eta}}{K_{\beta} \Delta^{o}}
\end{aligned}
$$

where $K_{\beta}$ is a mode-dependent interfacial stiffness defined as:

$$
K_{\beta}=K_{n}(1-\beta)+\beta K_{s h}
$$

and $\beta$ is the local mixed mode ratio defined as:

$$
\beta=\frac{K_{s h} \Delta_{s h}^{2}}{K_{s h} \Delta_{s h}^{2}+K_{n}\left\langle-\Delta_{n}\right\rangle^{2}}
$$

The damage variable is given by:

$$
d=\frac{r_{d} \Delta^{f}}{r_{d} \Delta^{f}+\left(1-r_{d}\right) r_{d} \Delta^{o}}
$$

\section{Numerical Results}

Both the continuum damage model developed to simulate intralaminar damage onset and propagation in composite laminates presented in Section 2.1, and the cohesive zone model to simulate delamination presented in Section 2.2, were developed with the goal of increasing the ability of the model to accurately predict damage propagation when though-thickness stresses are not negligible, and/or under compressive loading conditions. In fact, when combined, the previous versions of the models $[16-18,55]$ were able to predict the in-plane mechanical behaviour of quasi isotropic and symmetric composite laminates with good accuracy in test cases where the triaxility of stresses was fairly negligible, such as open-hole tension and open-hole compression. Camanho et al. [57] used the continuum damage model proposed in Refs. [16-18] to simulate 
the damage propagation in five open-hole tension tests of IM7/8552 cabon/epoxy system and obtained a maximum error of $10.5 \%$ and a mean error of $4.2 \%$. Bessa [58] predicted the openhole tensile and compressive strength of IM7/8552 carbon/epoxy material system by combining the continuum damage model [16-18] and the cohesive zone model presented in Ref. [55]. For the open-hole tensile strengths, a maximum error of $11.5 \%$ and a mean error of $5.0 \%$ were obtained; for the open-hole compressive strengths, the maximum error and the mean error were of $16.5 \%$ and $11.6 \%$, respectively. Note that relative errors between the mean strength measured experimentally and the one predicted numerically are usually considered acceptable when below 10\%, hence, the predictions obtained by Bessa [58] and Camanho et al. [57] for tensile loading are particularly accurate in both studies while, the open-hole compressive strengths were slightly over-predicted [58]. This could be attributed to the fact that compressive strengths are more difficult to predict because the damage mechanisms are more complex; however, since they are remarkably consistent, i.e. the errors across the different geometries are similar, it was attributed to the inaccuracy of the experimental value available for the fracture toughness for longitudinal compression. As will be detailed in Section 3.4, the original versions of the models failed to deliver accurate predictions for more complex cases with significant compressive throughthickness stresses, simply because the material model for intralaminar damage was developed assuming that the components of the out-of-plane stresses are too small to affect damage, and also because the cohesive zone model was not developed accounting for frictional effects.

To validate the proposed modelling strategy, experimental results of unnotched tension/ compression, open-hole tension/ compression and filled hole compression of multidirectional laminates are compared with finite element results. Open-hole tension and compression tests were simulated to ensure that the modifications reported in Sections 2.1 and 2.2 do not affect the predictions previously obtained for these test cases [57, 58]. Filled-hole compression tests are considered the main test case to evaluate the accuracy of the modelling strategy since the pressure applied by the bolt can be significant, and therefore, accounting for the effect of friction and the effect of the through-thickness stresses in the formulation becomes more important. Filled-hole compression simulations are, therefore, analysed with more detail.

Both open-hole tension and compression Finite Element (FE) models used one 8-node linear brick reduced integration element $(\mathrm{C} 3 \mathrm{D} 8 \mathrm{R})$ per ply thickness, $t$, and the plies are connected by $0.01 \mathrm{~mm}$ thick COH3D 8 user material cohesive elements. The laminate is clamped on one end while on the other a displacement (through the definition of an appropriate smooth step amplitude) is applied to all nodes at the boundary. A mesh of $0.5 \times 0.5 \times t \mathrm{~mm}^{3}$ is used for ply 
elements and $0.5 \times 0.5 \times 0.01 \mathrm{~mm}^{3}$ for the cohesive elements (see Fig. 8). A similar strategy was used to model the unnotched tension and compression specimens, however, in these cases, two linear elastic regions were modelled respectively on the upper and bottom side of the specimen and were connected to the laminate in order to avoid premature failure of the elements where the boundary conditions are applied. For the unnotched tension and compression models, a mesh of $0.25 \times 0.25 \times t \mathrm{~mm}^{3}$ is used for ply elements and $0.25 \times 0.25 \times 0.01 \mathrm{~mm}^{3}$ for the cohesive elements (see Fig. 9).

The filled hole compression model is composed by i) one bolt using of C3D8R elastic elements, ii) an upper and a lower bushing using C3D8R elastic elements, iii) the laminate. One C3D8R finite element per ply is used to simulate intralaminar damage and the plies are connected by 0.01mm thick COH3D8 user material cohesive elements. The pre-loading of the bolt is simulated by increasing the temperature of the upper bushing. The temperature applied to the upper bushing was calibrated so that the preload of the bolt matches the experimental values. The laminate is clamped on the lower end and a smooth step is applied to the upper end of the laminate. A mesh of $0.47 \times 0.47 \times t \mathrm{~mm}^{3}$ is used for ply elements and $0.47 \times 0.47 \times 0.01 \mathrm{~mm}^{3}$ for the cohesive elements (see Fig. 10). The material properties of the three material systems used are presented in Tables 1-5. Nominal values without standard deviation are provided for the experimental inputs to the models. In Appendix A, the material properties are defined and methods for their experimental determination are given.

Geometry definition

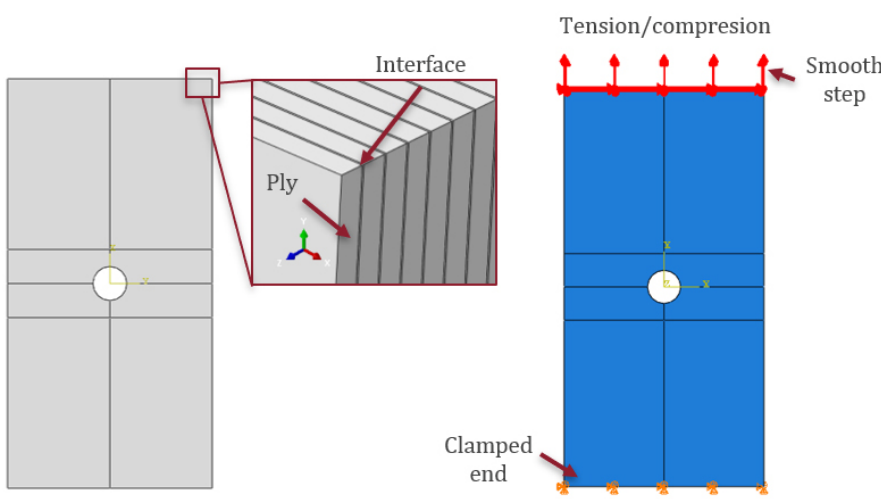

Mesh definition

User defined COH3D8 elements $0.5 \times 0.5 \times 0.01 \mathrm{~mm}^{3}$

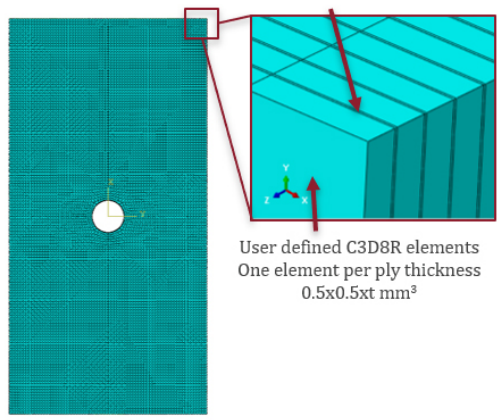

Figure 8: Finite element models for open-hole tension and compression. 

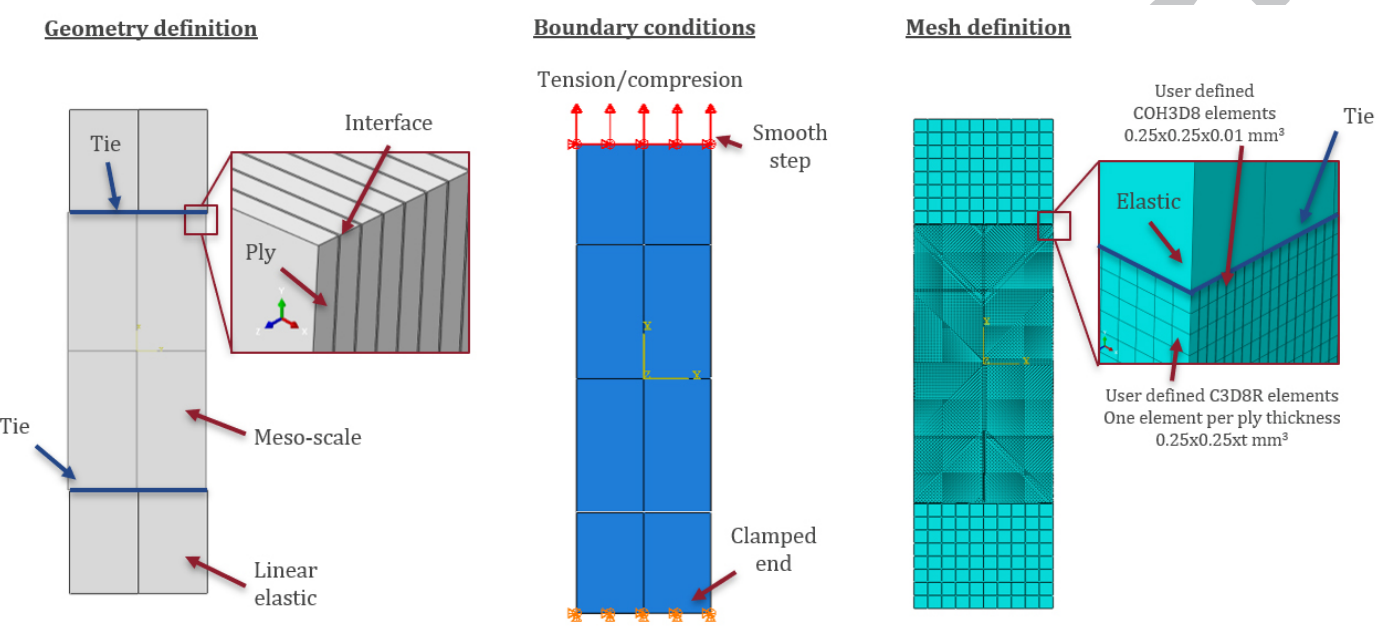

Figure 9: Finite element models for unnotched tension and compression. 

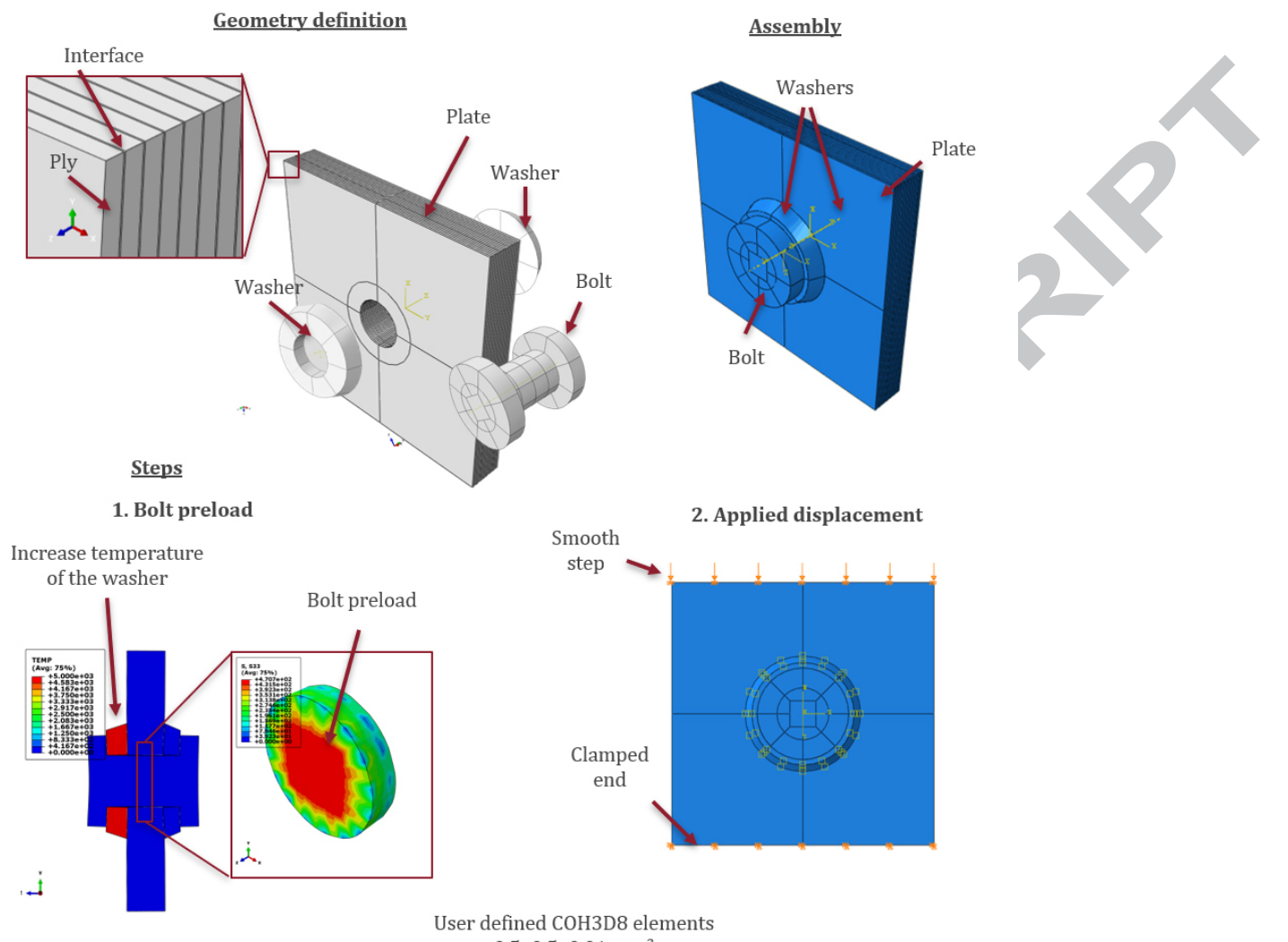

2. Applied displacement ncrease temperature

step
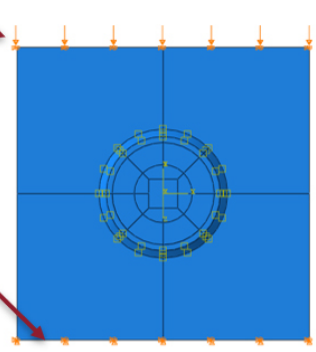

Mesh definition

User defined COH3D8 elements
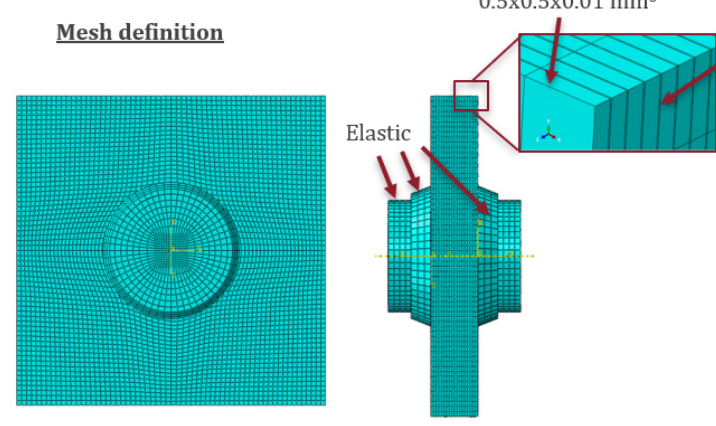

User defined C3D8R elements One element per ply thickness $0.5 \times 0.5 \times \mathrm{mm}^{3}$

Figure 10: Finite element models for filled-hole compression. 


\section{ACCEPTED MANUSCRIPT}

Table 1: Ply elastic properties of IM7/8552, T800/M21 and T700/M21 carbon/epoxy systems.

\begin{tabular}{llllllll}
\hline \multicolumn{2}{c}{ Elastic } & \multicolumn{2}{c}{ IM7/8552 } & \multicolumn{2}{c}{ T800/M21 } & \multicolumn{2}{c}{ T700/M21 } \\
\hline$E_{1}$ & $(\mathrm{MPa})$ & 171420 & Ref. [7, 57$]$ & 172000 & Ref. [59] & 171200 & Ref. [60] \\
$E_{1 c}$ & $(\mathrm{MPa})$ & 137136 & Note $(1)$ & 137600 & Note (1) & 137000 & Note (1) \\
$E_{2}$ & $(\mathrm{MPa})$ & 9080 & Ref. [7, 57$]$ & 8900 & Ref. [59] & 8500 & Ref. [60] \\
$G_{12}$ & $(\mathrm{MPa})$ & 5290 & Ref. [7, 57$]$ & 5000 & Ref. [59] & 4500 & Ref. [60] \\
$\nu_{12}$ & - & 0.32 & Ref. [7, 57$]$ & 0.32 & Ref. [59] & 0.32 & Ref. [60] \\
\hline
\end{tabular}

(1) Assumed to be $80 \%$ of the Young's Modulus for longitudinal tension $\left(E_{1 c}=0.8 E_{1}\right)$

Table 2: Ply strengths properties of IM7/8552, T800/M21 and T700/M21 carbon/epoxy systems.

\begin{tabular}{llllllll}
\hline \multicolumn{2}{l}{ Strengths } & \multicolumn{2}{c}{ IM7/8552 } & \multicolumn{2}{c}{ T800/M21 } & \multicolumn{2}{c}{ T700/M21 } \\
\hline$X_{T}$ & $(\mathrm{MPa})$ & 2323.5 & Ref. [7, 57] & 3039 & Ref. [61] & 2000 & Ref. [60] \\
$f_{X T}$ & $(-)$ & 0.4 & Ref. [61] & 0.4 & Ref. [61] & 0.4 & Note $(1)$ \\
$X_{C}$ & $(\mathrm{MPa})$ & 1200.1 & Ref. [7, 57] & 1051 & Ref. [62] & 1300 & Ref. [60] \\
$f_{X C}$ & $(-)$ & 0.2 & Note $(2)$ & 0.2 & Note $(2)$ & 0.2 & Note $(3)$ \\
$Y_{T}$ & $(\mathrm{MPa})$ & 62.3 & Ref. [7, 57] & 75 & Ref. [61] & 46 & Ref. [63] \\
$Y_{C}$ & $(\mathrm{MPa})$ & 253 & Ref. [7, 57] & 250 & Ref. [61] & 260 & Ref. [63] \\
$Y_{B T}$ & $(\mathrm{MPa})$ & 38.7 & Ref. [19, 30] & 46.5 & Note $(4)$ & 28.5 & Note $(4)$ \\
$Y_{B C}$ & $(\mathrm{MPa})$ & 600.0 & Ref. [19, 30] & 592.5 & Note (5) & 616.2 & Note (5) \\
$S_{L}$ & $(\mathrm{MPa})$ & 92.3 & Ref. [7, 57] & 95 & Ref. [61] & 81 & Ref. [63] \\
$S_{L}^{P}$ & $(\mathrm{MPa})$ & 66.9 & Note $(6)$ & 66.9 & Note $(6)$ & 50 & Note $(6)$ \\
$K_{p}$ & $(-)$ & 0.08 & Note $(6)$ & 0.09 & Note $(6)$ & 0.29 & Note $(6)$ \\
\hline
\end{tabular}

(1) Assumed from the IM7/8552 material system

(2) Inversely identified using one OHC simulation

(3) Inversely identified using one FHC simulation

(4) The ratio $Y_{B T} / Y_{T}$ was assumed to be constant and equal to $Y_{B T} / Y_{T}=38.7 / 62.3=0.62$

(5) The ratio $Y_{B C} / Y_{C}$ was assumed to be constant and equal to $Y_{B C} / Y_{C}=600.0 / 253.0=2.37$

(6) Best fitting from the transverse shear stress-strain curve of the material 


\section{ACCEPTED MANUSCRIPT}

Table 3: Ply fracture toughness of IM7/8552, T800/M21 and T700/M21 carbon/epoxy systems.

\begin{tabular}{llllllll}
\hline \multicolumn{2}{c}{ Fracture } & \multicolumn{2}{c}{ IM7/8552 } & \multicolumn{2}{c}{ T800/M21 } & \multicolumn{2}{c}{ T700/M21 } \\
\hline $\mathcal{G}_{2+}$ & $\left(\mathrm{kJ} / \mathrm{m}^{2}\right)$ & 0.28 & Ref.[7, 57] & 0.228 & Ref. [61] & 0.35 & Ref. [63] \\
$\mathcal{G}_{2-}$ & $\left(\mathrm{kJ} / \mathrm{m}^{2}\right)$ & 1.31 & Note $(1)$ & 1.0 & Note $(1)$ & 2.0 & Note $(1)$ \\
$\mathcal{G}_{6}$ & $\left(\mathrm{~kJ} / \mathrm{m}^{2}\right)$ & 0.79 & Ref.[7, 57] & 0.652 & Ref. [61] & 1.2 & Ref. [63] \\
$\mathcal{G}_{1+}$ & $\left(\mathrm{kJ} / \mathrm{m}^{2}\right)$ & 133.3 & Ref. [58] & 340 & Ref. [61] & 133.3 & Note $(2)$ \\
$f_{G T}$ & $(-)$ & 0.3 & Note (3) & 0.52 & Ref. [61] & 0.52 & Note $(4)$ \\
$\mathcal{G}_{1-}$ & $\left(\mathrm{kJ} / \mathrm{m}^{2}\right)$ & 61 & Ref. [64] & 60 & Note $(5)$ & 95 & Note $(6)$ \\
\hline
\end{tabular}

(1) $\mathcal{G}_{2-}=\mathcal{G}_{6} / \cos \left(\alpha_{0}\right)$ where $\mathcal{G}_{6}$ is the mode II fracture toughness and $\alpha_{0}$ is the fracture angle of the UD ply subjected to uniaxial transverse compression (approximately $53^{\circ}$ )

(2) Assumed from the IM7/8552 material system

(3) Inversely identified using one OHT simulation

(4) Assumed from the T800/M21 material system

(5) Inversely identified using one OHC simulation

(6) Inversely identified using one FHC simulation

Table 4: Ply geometric and friction parameters of IM7/8552, T800/M21 and T700/M21 carbon/epoxy systems.

\begin{tabular}{|c|c|c|c|c|c|c|}
\hline \multicolumn{2}{|c|}{ Geometrical } & IM7/8552 & \multicolumn{2}{|c|}{ T800/M21 } & \multicolumn{2}{|c|}{ T700/M21 } \\
\hline$\alpha_{0}$ & $(\mathrm{rad})$ & 0.925 & 0.925 & - & 0.925 & - \\
\hline$t$ & $(\mathrm{~mm})$ & 0.125 & $0.125 / 0.184$ & - & 0.250 & - \\
\hline \multicolumn{7}{|c|}{ Friction } \\
\hline$\eta_{G}$ & $\left(\mathrm{MPa}^{-1}\right)$ & Note $(1)$ & 0.0035 & Note $(1)$ & 0.0035 & Note $(1)$ \\
\hline$f_{f x c}$ & $\left(\mathrm{MPa}^{-1}\right)$ & $0.01 \quad$ Note $(2)$ & 0.01 & Note $(2)$ & 0.01 & Note $(2)$ \\
\hline
\end{tabular}

(1) Assumed to be equal to the $\eta$ parameter that accounts for the increase in interlaminar mode II fracture toughness as a function of applied through-thickness compressive stress determined for the IM7/8552 carbon/epoxy material system in Ref. [36]

(2) Inversely identified from a OHC or FHC simulation 
Table 5: Interlaminar material properties.

\begin{tabular}{|c|c|c|c|c|c|c|c|}
\hline \multicolumn{2}{|c|}{ Elastic } & \multicolumn{2}{|c|}{ IM7/8552 } & \multicolumn{2}{|c|}{ T800/M21 } & \multicolumn{2}{|c|}{ T700/M21 } \\
\hline$K_{n}$ & $\left(\mathrm{~N} / \mathrm{mm}^{3}\right)$ & $10^{6}$ & Ref. [65] & $10^{6}$ & Ref. [65] & $10^{6}$ & Ref. [65] \\
\hline \multicolumn{8}{|c|}{ Strengths } \\
\hline$\tau_{N}$ & $(\mathrm{MPa})$ & 62.3 & Ref. $[7,57]$ & 75 & Ref. [61] & 46 & Ref. [63] \\
\hline$\tau_{s h}$ & $(\mathrm{MPa})$ & 92.3 & Ref. $[7,57]$ & 95 & Ref. [61] & 81 & Ref. [63] \\
\hline \multicolumn{8}{|c|}{ Fracture } \\
\hline $\mathcal{G}_{I C}$ & $\left(\mathrm{~kJ} / \mathrm{m}^{2}\right)$ & 0.28 & Ref. $[7,57]$ & 0.228 & Ref. [61] & 0.35 & Ref. [63] \\
\hline $\mathcal{G}_{I I C}$ & $\left(\mathrm{~kJ} / \mathrm{m}^{2}\right)$ & 0.79 & Ref. $[7,57]$ & 0.652 & Ref. [61] & 1.2 & Ref. [63] \\
\hline$\eta_{B-K}$ & $(-)$ & 1.45 & Ref. $[66,67]$ & 1.45 & Note (1) & 2.0 & Ref. [63] \\
\hline \multicolumn{8}{|c|}{ Friction } \\
\hline$\mu$ & $(-)$ & 0.1 & Ref. [36] & 0.1 & Ref. [36] & 0.1 & Ref. [36] \\
\hline
\end{tabular}

(1) Assumed from the IM7/8552 carbon/epoxy material system

\subsection{Unnotched Strength}

Figure 11 shows the experimental results for unnotched tensile and unnotched compressive strengths and the predictions obtained with the proposed modelling strategy for a quasi-isotropic $[90 / 0 /-45 / 45]_{3 s}$ IM7/8552 laminate. The relative error for unnotched tensile strength is $-13.1 \%$ and $-4.7 \%$ for unnotched compressive strength. As shown in Figs. 12 and 13, modelled damage localizes at the $0^{\circ}$ plies causing catastrophic failure of the specimen.

\subsection{Open-hole tension}

Figures 14-16 show the experimental results for open-hole tensile strengths and the predictions obtained with the proposed modelling strategy for a $[90 / 0 /-45 / 45]_{3 s}$ IM7/8552 laminate and two quasi-isotropic T800/M21 laminates: $[90 / 45 / 0 /-45]_{3 s}$ (L1) and $\left[90_{2} / 0_{2} / 45_{2} /-45_{2} / 90 / 0 / 45 /-45\right]_{s}$ (L2). For the IM7/8552 material system, the maximum relative error is $7.9 \%$ for hole diameter $d=8 \mathrm{~mm}$ while the mean error is $5.3 \%$. For T800/M21 material system, the relative errors for the two layups are below $10.7 \%$ and the mean error is $3.9 \%$. The predictions for laminate L1 are more accurate than the ones for laminate L2. Both layups are quasi-isotropic, but L2 has plies with the same orientation blocked together. Having thicker $0^{\circ}$ plies in a laminate promotes fibre splitting, which blunts the notch and improves the notched strength [68-71], resulting in an apparent increase of the fracture toughness of the laminate. However, the modelling strategy used, which 


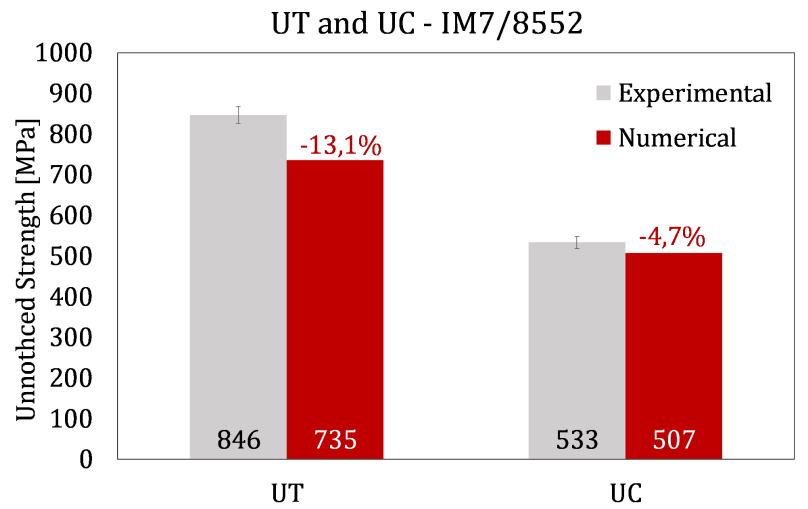

Figure 11: Comparison between the numerical and experimental results for the unnotched tensile and compressive strengths of an IM7/8552 carbon/epoxy quasi-isotropic laminate. The standard error related to the experimental test results is presented.
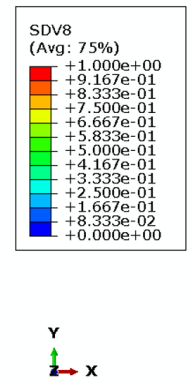

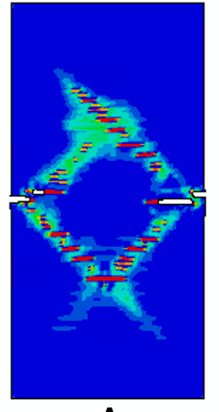

A

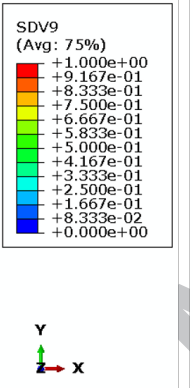

$x \rightarrow x$

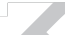

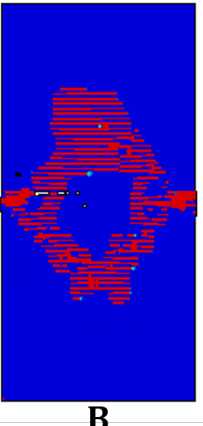

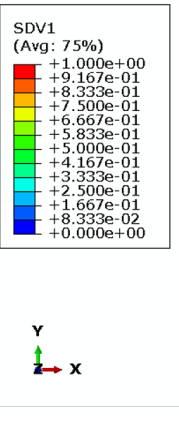

B

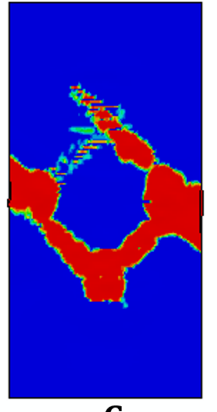

C

Figure 12: Damage extent at ultimate load in the unnotched tension simulation: A) fibre damage in a $0^{\circ}$ ply $\left(d_{1}\right)$, B) matrix damage in a $90^{\circ}\left(d_{2}\right)$, C) interface damage $(d)$. The specimen presented in this figure corresponds to the $[90 / 0 /-45 / 45]_{3 s}$ IM7/8552 laminate.

is not based on structured meshes, is likely not able to accurately predict fibre splitting in the $0^{\circ}$ plies and to distinguish blocked $0^{\circ}$ plies of single $0^{\circ}$ plies. An accurate prediction of splitting would require a more refined mesh, accounting for large deformation/rotations in the model formulation [72], and the use of structured, fibre-aligned meshes where the edges of the elements follow the fibre direction [73] .

In general, at the point of maximum load the fibre damage in the $0^{\circ}$ plies localizes in the vicinity of the hole and propagates perpendicular to the applied load (Fig. 17.A); the matrix 


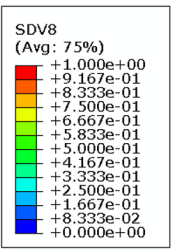

$\mathbf{r}$

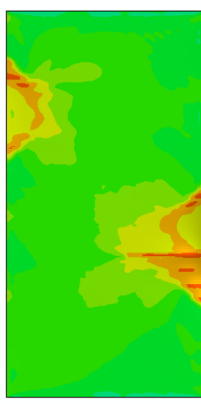

A

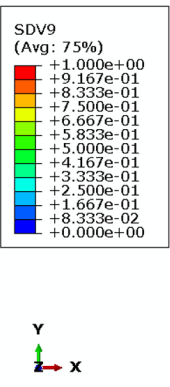

$1 \rightarrow x$

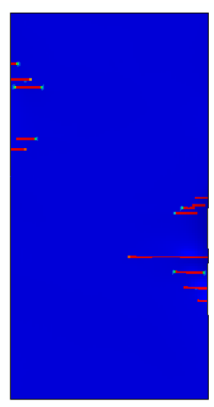

B

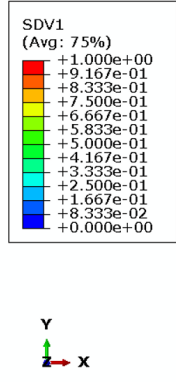

$L_{x}$

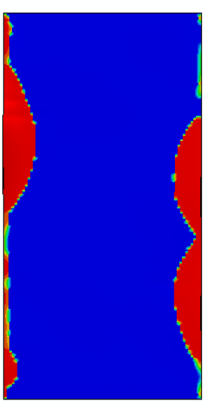

C

Figure 13: Damage extent at ultimate load in the unnotched compression simulation: A) fibre damage in a $0^{\circ}$ ply $\left(d_{1}\right)$, B) matrix damage in a $90^{\circ}\left(d_{2}\right)$, C) interface damage $(d)$. The specimen presented in this figure corresponds to the $[90 / 0 /-45 / 45]_{3 s}$ IM7/8552 laminate.

damage in the $90^{\circ}$ plies extends across the width of the specimen (Fig. 17.B); and interface damage is limited to the ligaments next to the hole (Fig. 17.C).

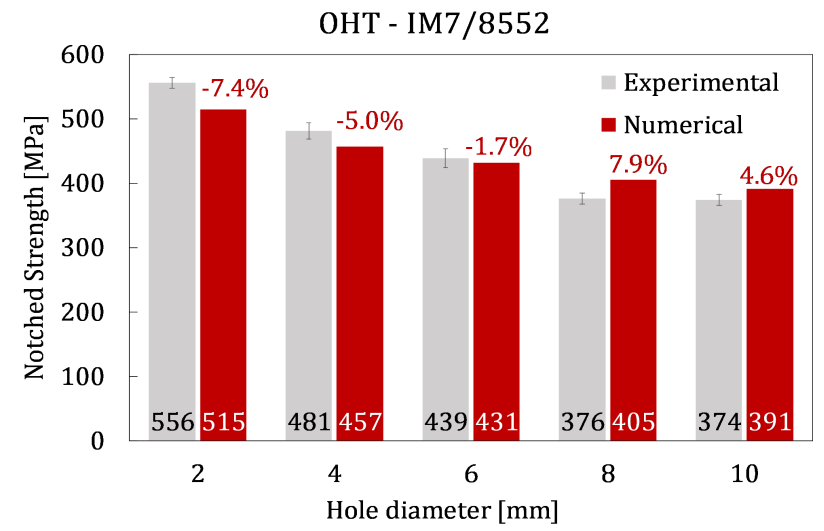

Figure 14: Comparison between the numerical and experimental results for the open-hole tensile strength of an IM7/8552 carbon/epoxy quasi-isotropic laminate [57]. The hole diameter-to-width ratio is $2 R / W=1 / 6$. The standard error related to the experimental test results is presented.

\subsection{Open-hole compression}

Figures 18-20 show the experimental results for open-hole compressive strengths and the predictions obtained with the proposed modelling strategy for the same material systems previously considered. For IM7/8552, the relative errors are below $4.4 \%$ and the mean error is $1.9 \%$. For T800/M21 material system, the relative errors for the two layups are below $12.8 \%$ and the mean 


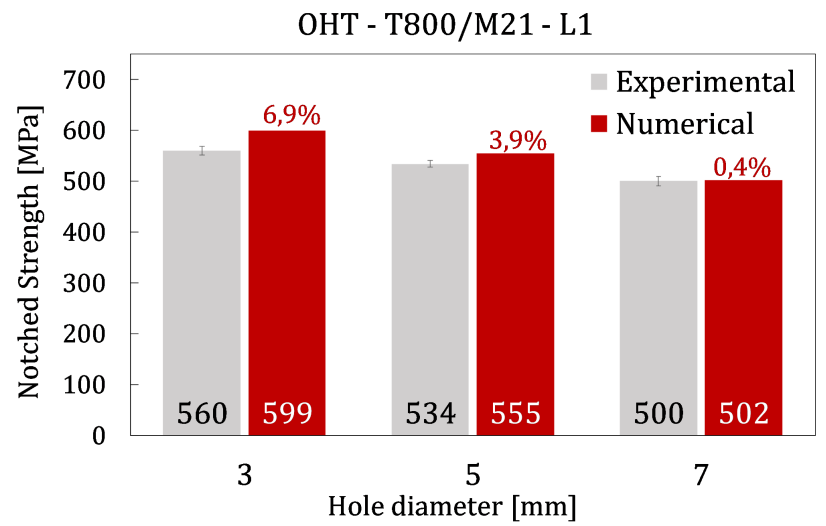

Figure 15: Comparison between the numerical and experimental results for the open-hole tensile strength of an T800/M21 carbon/epoxy quasi-isotropic laminate (L1) [70]. The hole diameter-to-width ratio is $2 R / W=1 / 4$. The standard error related to the experimental test results is presented.

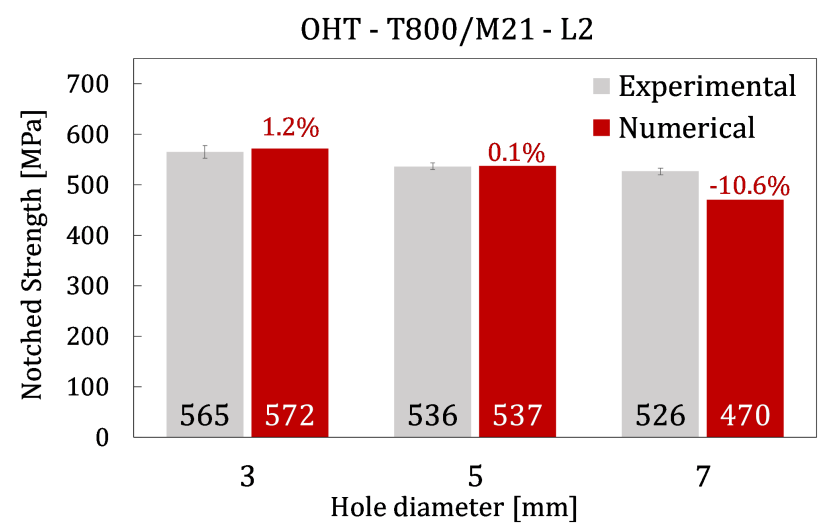

Figure 16: Comparison between the numerical and experimental results for the open-hole tensile strength of a T800/M21 carbon/epoxy quasi-isotropic laminate (L2) [70]. The hole diameter-to-width ratio is $2 R / W=1 / 4$. The standard error related to the experimental test results is presented.

error is $7.6 \%$. The predictions for IM7/8552 material system are significantly improved compared with the predictions obtained by Bessa [58] (maximum error of $16.5 \%$ and mean error of $11.6 \%$ ). Here, the fracture toughness for longitudinal compression used was determined by Catalanotti et al. [64]. This value is lower than the one used by Bessa [58] which explains why the errors obtained are, on average, around 10\% lower. The experimental results for open-hole compression for the L2 T800/M21 layup that uses thicker ply blocks shows a pronounced size effect that is not predicted very accurately by the model. This lower consistency in the predictions may be due to the fact that the material was not fully characterized and therefore, some assumptions on the 


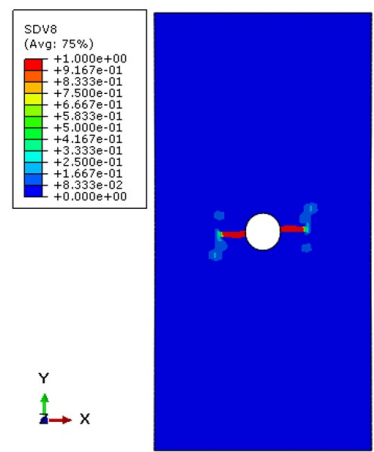

$\mathbf{A}$

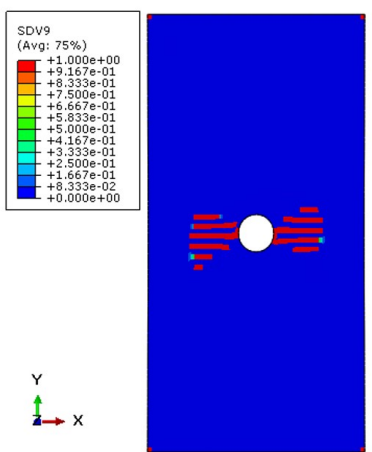

B

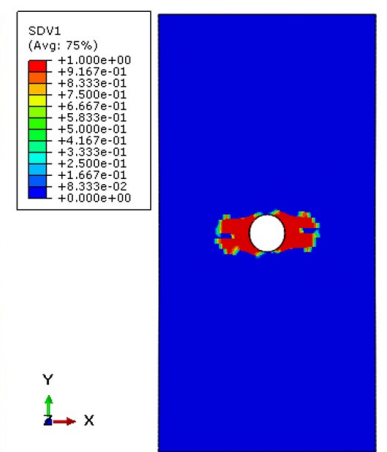

C

Figure 17: Typical damage extent at ultimate load in an open-hole tension simulation: A) fibre damage in a $0^{\circ}$ ply $\left(d_{1}\right)$, B) matrix damage in a $90^{\circ}$ ply $\left(d_{2}\right)$, C) interface damage $(d)$. The specimen presented in this figure corresponds to the $[90 / 0 /-45 / 45]_{3 s}$ IM7/8552 laminate with a hole diameter of $d=6 \mathrm{~mm}$.

material properties had to be made by the authors, particularly on the longitudinal compressive strength and fracture toughness for longitudinal compression of the unidirectional ply.

Across the materials and layups considered, the OHC response has the general features that, at the point of maximum load, damage localizes at the vicinity of the hole as shown in Fig. 21: fibre damage in the $0^{\circ}$ plies extends across the width of the specimen (Fig. 21.A), matrix damage in the $90^{\circ}$ plies localizes in the vicinity of the hole and propagates perpendicularly to the applied load (Fig. 21.B), and interface damage is limited to the area of the hole (Fig. 21.C).

\subsection{Filled-hole compression}

Filled-hole compression simulations are analysed with more detail since the pressure applied by the bolt can be significant, and therefore, accounting for frictional effects and the effect of the through-thickness stress in the formulation becomes critical. It is important to note that, even though the previous versions of the models were not particularly suitable for test cases where the triaxility of stresses is not negligible, some engineering solutions proposed by several authors $[37,38,51,52]$ can be used to improve the accuracy in the presence of though-thickness stresses. It is, therefore, interesting to compare four modelling strategies (S1 through S4). Note that S3 and $\mathrm{S} 4$ are based on the work presented in this paper:

- S1 - Intralaminar damage is simulated using the user-written material subroutine described in Refs. [16-18] and interlaminar damage is simulated using built-in ABAQUS cohesive 


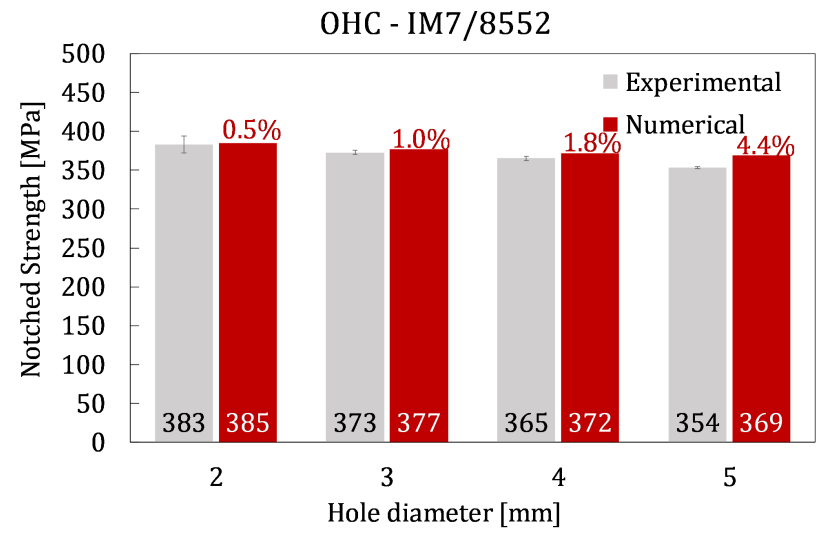

Figure 18: Comparison between the numerical and experimental results for the open-hole compressive strength of an IM7/8552 carbon/epoxy quasi-isotropic laminate [58]. The hole diameter-to-width ratio is $2 R / W=1 / 6$. The standard error related to the experimental test results is presented.

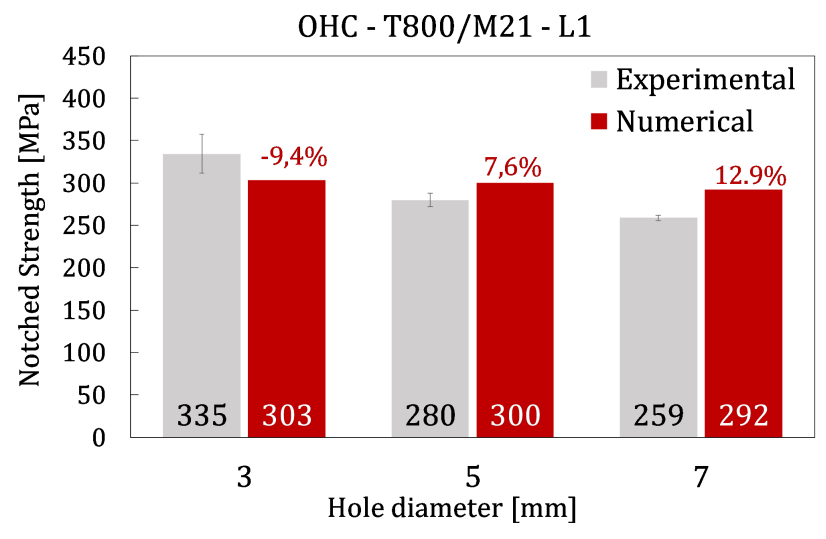

Figure 19: Comparison between the numerical and experimental results for the open-hole compressive strength of an T800/M21 carbon/epoxy quasi-isotropic laminate (L1) [70]. The hole diameter-to-width ratio is $2 R / W=1 / 4$. The standard error related to the experimental test results is presented.

\section{elements [74].}

- S2 - Intralaminar damage is simulated using the user-written material subroutine described in Refs. [16-18] and interlaminar damage is simulated using built-in ABAQUS cohesive elements [74]. Engineering solutions proposed by Turon and co-authors. [51, 52] and by Cui et al. [37] are used to calculate some of the properties of the cohesive elements to ensure proper energy dissipation in mixed-mode loadings and to artificially account for the effects of pressure and friction. These solutions are summarized in Appendix C. 


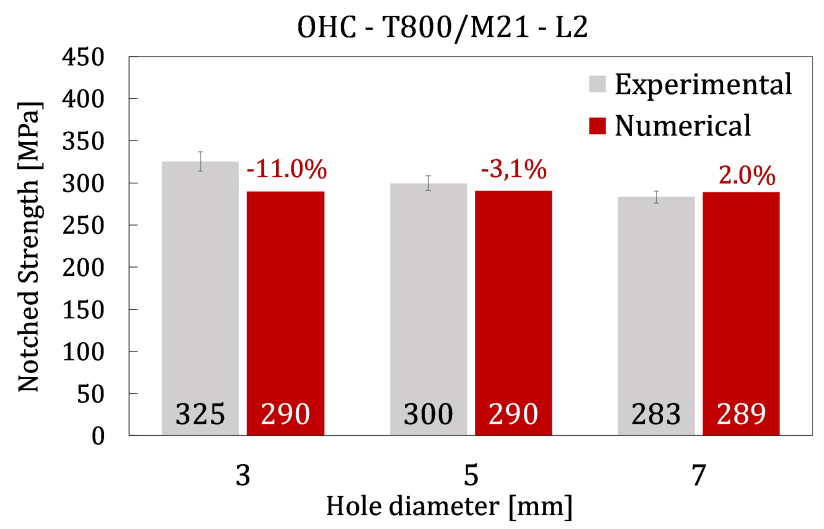

Figure 20: Comparison between the numerical and experimental results for the open-hole compressive strength of a T800/M21 carbon/epoxy quasi-isotropic laminate (L2) [70]. The hole diameter-to-width ratio is $2 R / W=1 / 4$. The standard error related to the experimental test results is presented.

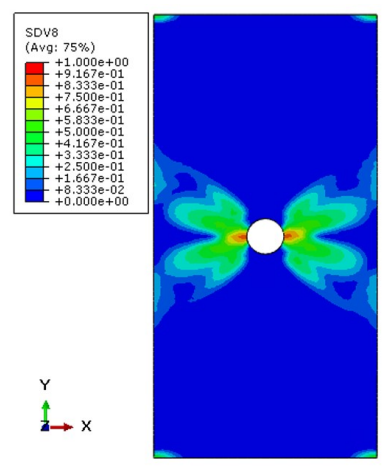

A

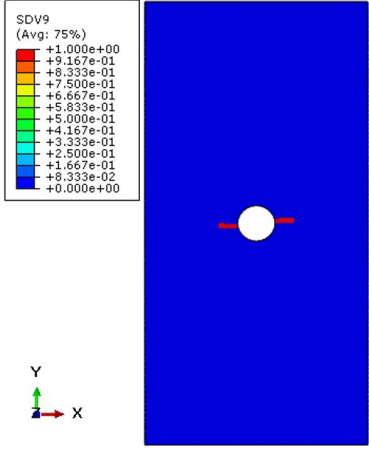

B

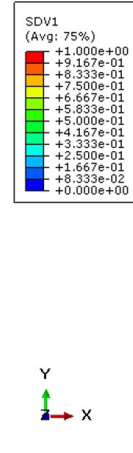

$\varliminf_{i x}$

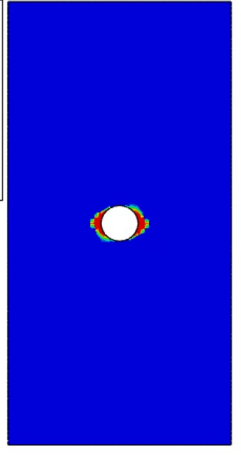

C

Figure 21: Typical damage extent at ultimate load in an open-hole compression simulation: A) fibre damage in a $0^{\circ}$ ply $\left(d_{1}\right)$, B) matrix damage in a $90^{\circ}$ ply $\left(d_{2}\right)$, C) interface damage $(d)$. The specimen presented in this figure corresponds to the $[90 / 0 /-45 / 45]_{3 s}$ IM7/8552 laminate with a hole diameter of $d=4 \mathrm{~mm}$.

- S3 - Intralaminar damage is simulated using the user-written material subroutine described in Section 2.1 and interlaminar damage is simulated using built-in ABAQUS cohesive elements [74]. The same engineering solutions [37, 51, 52] used in S2 are used here. These solutions are also summarized in Appendix C.

- S4 - Intralaminar damage is simulated using the user-written material subroutine described in Section 2.1 and interlaminar damage is simulated using the user-written material subroutine described in Section 2.2, i.e., the $\mathrm{S} 4$ is the application of the new formulation presented 
in this paper.

Two simulations are performed with two different T700/M21 layups: 44/44/11 where 44.4(4)\%, $44.4(4) \%$ and $11.1(1) \%$ of the plies are $0^{\circ}, \pm 45^{\circ}$ and $90^{\circ}$, respectively, and $11 / 44 / 44$ where $11.1(1) \%, 44.4(4) \%$ and $44.4(4) \%$ of the plies are $0^{\circ}, \pm 45^{\circ}$ and $90^{\circ}$, respectively. Note that $11 / 44 / 44$ stands for a $90^{\circ}$ rotation of $44 / 44 / 11$. The stacking sequences of the laminates, the experimental filled-hole compression strengths and load-displacement curves are Airbus proprietary and are therefore not presented in absolute terms. However, their absence does not affect the key observations and conclusions of this section. The stress-displacement relations and the errors between the experimental and the normalized numerical notched strengths obtained are presented in Fig. 22. To better understand the consequences of each modelling strategy and to assess the most suitable one, the results of each simulation are analysed in detail. Given the stacking sequence, laminate $44 / 44 / 11$ will be referred to as the "hard laminate" and laminate $11 / 44 / 44$ will be referred to as the "soft laminate".

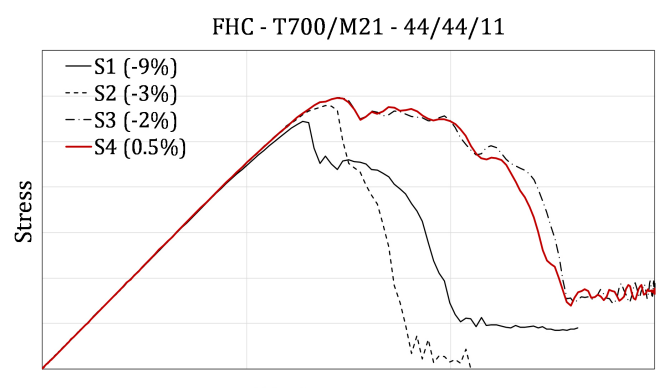

Displacement

(a)
FHC - T700/M21 - 11/44/44

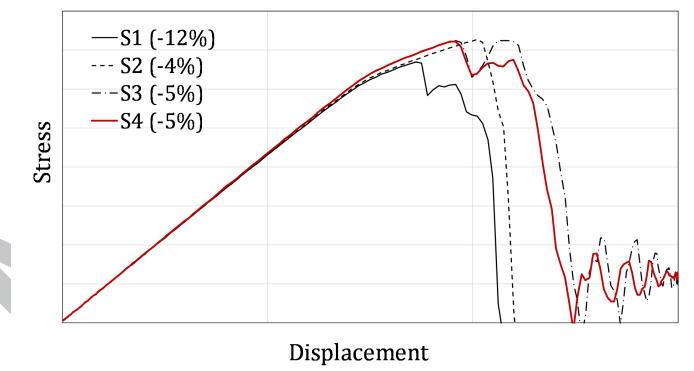

(b) S2

Figure 22: Filled-hole compression numerical stress-displacement curves for a) the hard laminate (44/44/11) and b) the soft laminate $(11 / 44 / 44)$ for the four modelling approaches S1 though S4. The legend provides the $\%$ difference between the model and experimental ultimate strength. Note that the $\mathrm{x}$ - and $\mathrm{y}$-axes in A and B are not the same.

- S1: Using the original modelling strategy, the ultimate strength for the hard and soft laminates are both slightly underpredicted by $-9 \%$ and $-12 \%$ respectively (see Fig. 22). More importantly, the model is not able to capture the post peak response and predicts that an abrupt, catastrophic failure will occur as shown in Fig. 22. In the hard laminate, failure is dominated by fibre failure (Fig. 23a.A and 24a.A) and, in the soft laminate, delamination develops around the hole and quickly propagates through the width of the specimen as shown in Fig. 23a.C. 
- S2: Using the modelling strategy 2, the mode II fracture toughness of the cohesive elements is increased as a function of the bolt pre-load. However, the pressure is not constant over all elements. In fact, the though-thickness stress is only negative under the bushings as shown in Fig. 25 and therefore, increasing the fracture toughness in all cohesive elements might result in an underprediction of the extent of delamination. In this case, failure is dominated by fibre compressive failure (figs. 23b.A and 24b.A) and delamination plays a less relevant role than in S1 (Figs. 23b.C and 24b.C).

- S3: Using the modelling strategy 3, the predicted filled-hole compressive ultimate strengths increase towards the experimental values. Similarly to modelling strategy 2 , the fracture toughness of the cohesive elements is equally increased and delamination might, therefore, be over-suppressed. Failure is progressive for two reasons. Firstly because delamination is partly suppressed, and secondly because the softening law for longitudinal compression was altered based on the experimental findings of Moran et al. [28], and therefore, even though damage in the $0^{\circ}$ is extensive, the $0^{\circ}$ plies do not fail completely as shown in Figs. 23c.A and 24c.A.

- S4: Finally, using the modelling strategy proposed in this work, the strengthening effect of pressure is more accurately represented since it is friction induced and not simply represented based on an empirical engineering solution. In the hard laminate, damage extension is similar to the one predicted using modelling strategy 3 because delamination does not play an important role in the failure of the specimen (Figs. 23c.C and 23d.C). However, for the soft laminate, unlike in S3, delamination propagates through the width of the specimen and its extent is similar to the one predicted using modelling strategy 1 ( Figs. 24a.C and 24d.C). It should be noticed that, even though the elements might be fully damaged, they are still able to carry load through friction.

To further explore the predictive capabilities of modelling strategy S4, other laminates were simulated using the same methodology. Figs. 26 and 27 show the experimental results for filled hole compressive strengths and the predictions obtained with the proposed modelling strategy for six multidirectional T700/M21 laminates and one multidirectional T800/M21 laminate, respectively. The relative errors for all seven layups are below $6.8 \%$ and the mean error is $2.7 \%$. The propagation of damage and eventual final failure is a complex combination of different failure mechanisms and interactions between matrix cracking, fibre failure and delamination. Note that the set of laminates tested include four hard and three soft laminates with different percentages 
of $0^{\circ}, 45^{\circ}$ and $90^{\circ}$ plies and that failure of each laminate is dominated by different failure modes. The load displacement curves were not available, and therefore, it was not possible to verify the accuracy of the simulations in predicting the evolution of applied stress as a function of the applied displacement. Nonetheless, the ability of the model to accurately predict the filled-hole compression ultimate strength is remarkable. 

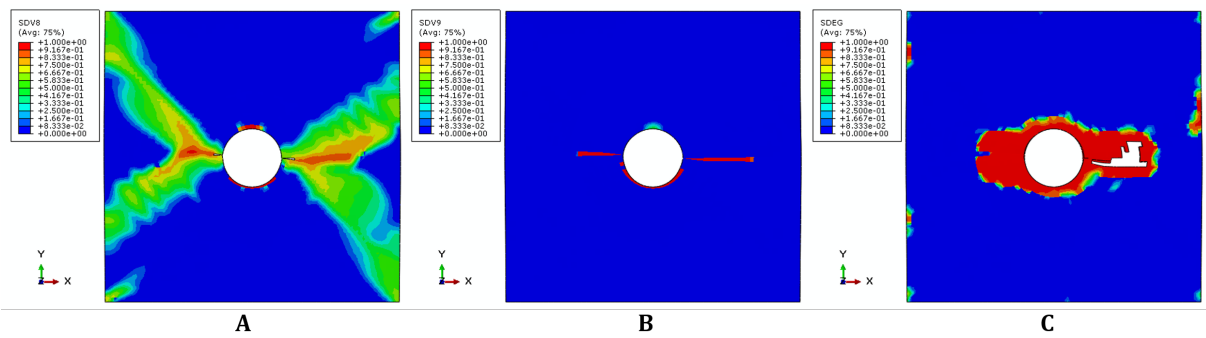

(a) $\mathrm{S} 1$

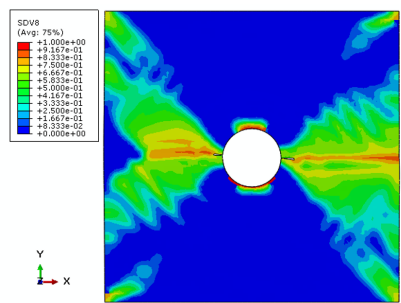

A
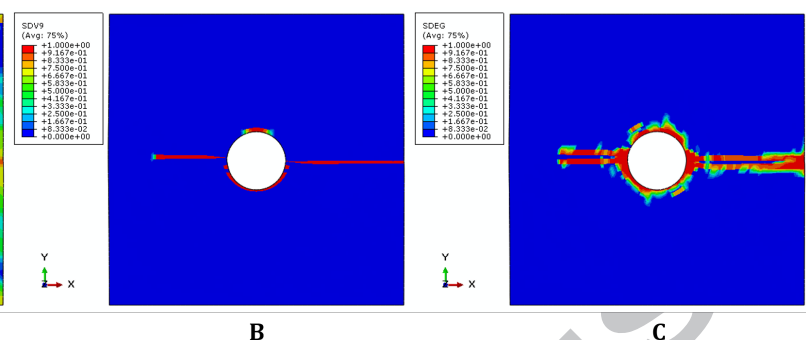

c

(b) S2
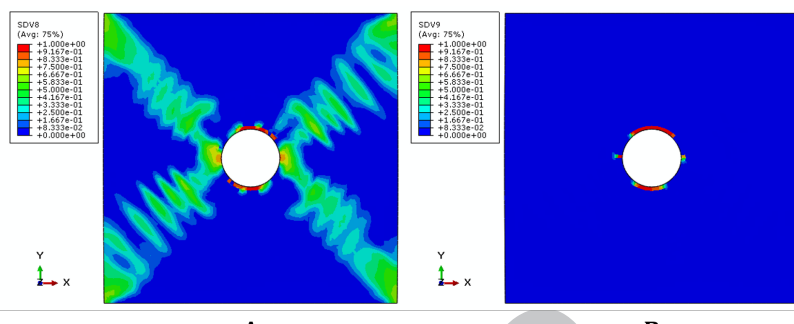

B

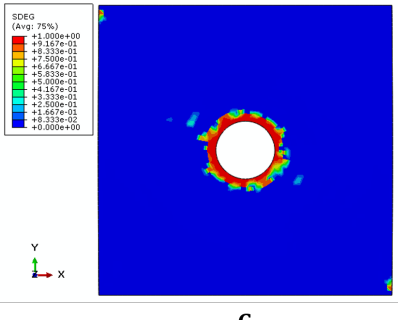

C

(c) S3

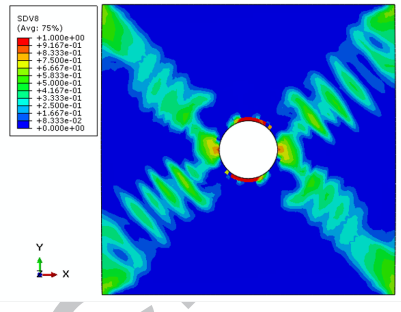

$$
\text { A }
$$

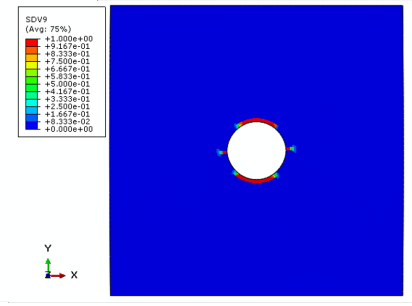

B

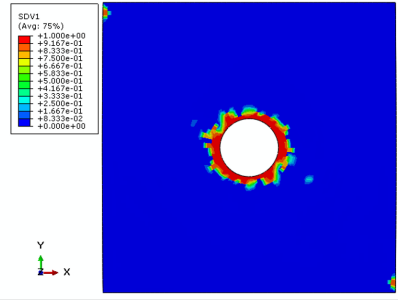

C

(d) S4

Figure 23: Predicted damage at ultimate load in 44/44/11: A) fibre damage in a $0^{\circ}$ ply $\left(d_{1}\right)$, B) matrix damage in a $90^{\circ}$ ply $\left(d_{2}\right)$, C) interface damage $(d)$. 

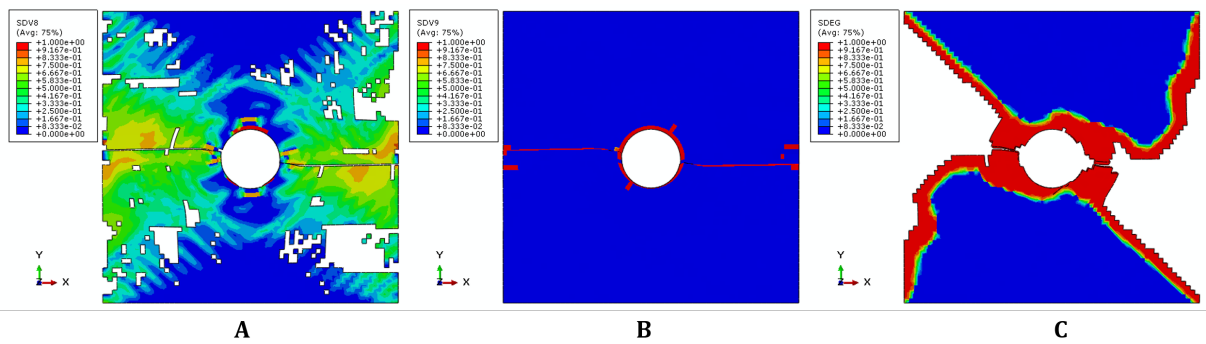

C

(a) S1
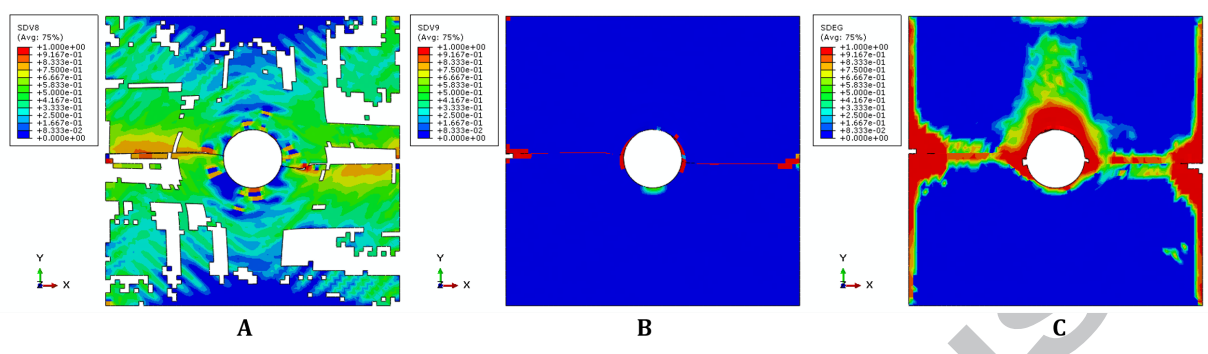

(b) S2

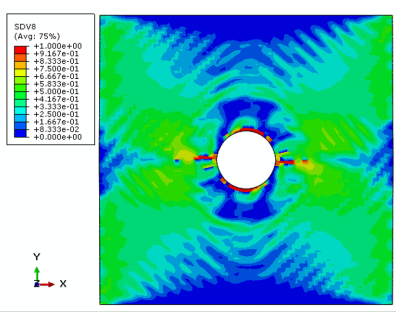

A

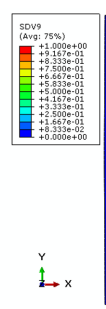

$\longrightarrow$

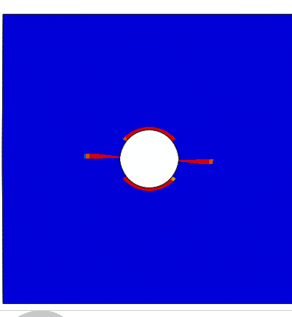

B

(c) S3
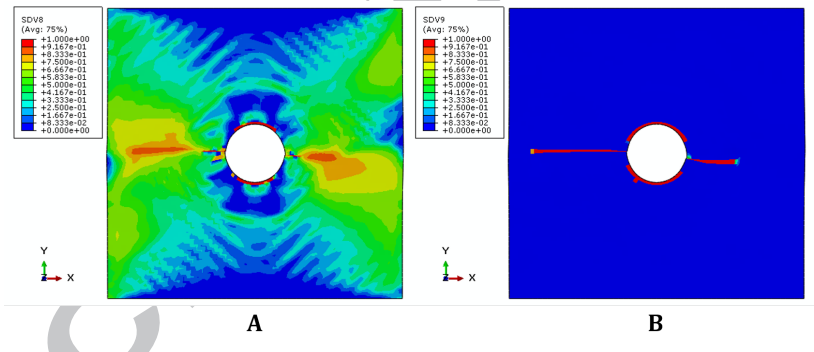

B

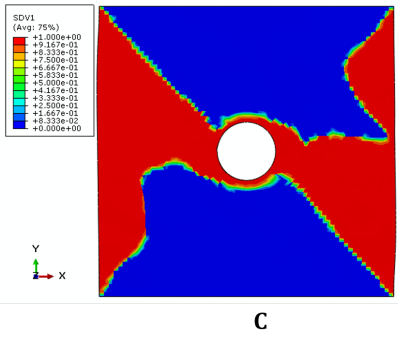

(d) S4

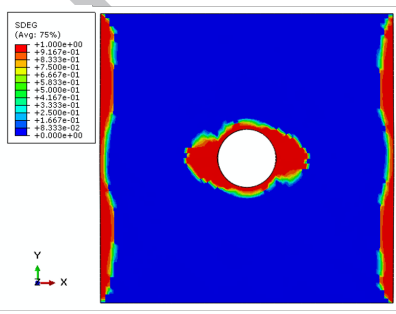

C 


\begin{tabular}{|c|}
\hline 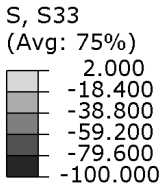 \\
\hline
\end{tabular}

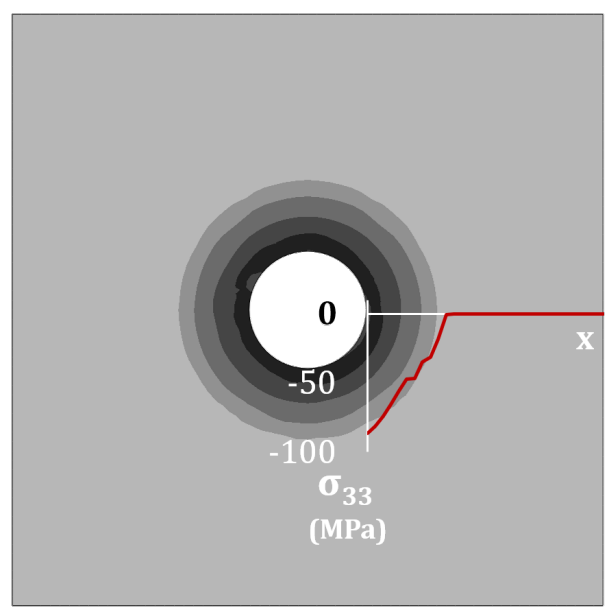

Figure 25: $\sigma_{33}$ (in $\mathrm{MPa}$ ) after bolt preload on the laminate of a filled hole compression specimen. $\sigma_{33}$ vs $x$ is plotted in red.

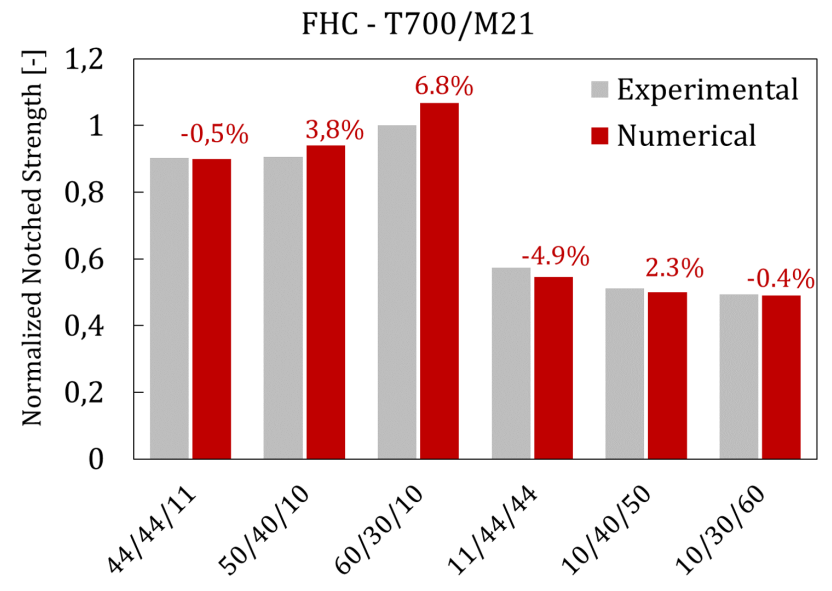

Figure 26: Comparison between the numerical and experimental results for the filled-hole compressive strength of six T700/M21 carbon/epoxy laminates. 
FHC - T800/M21 - L3
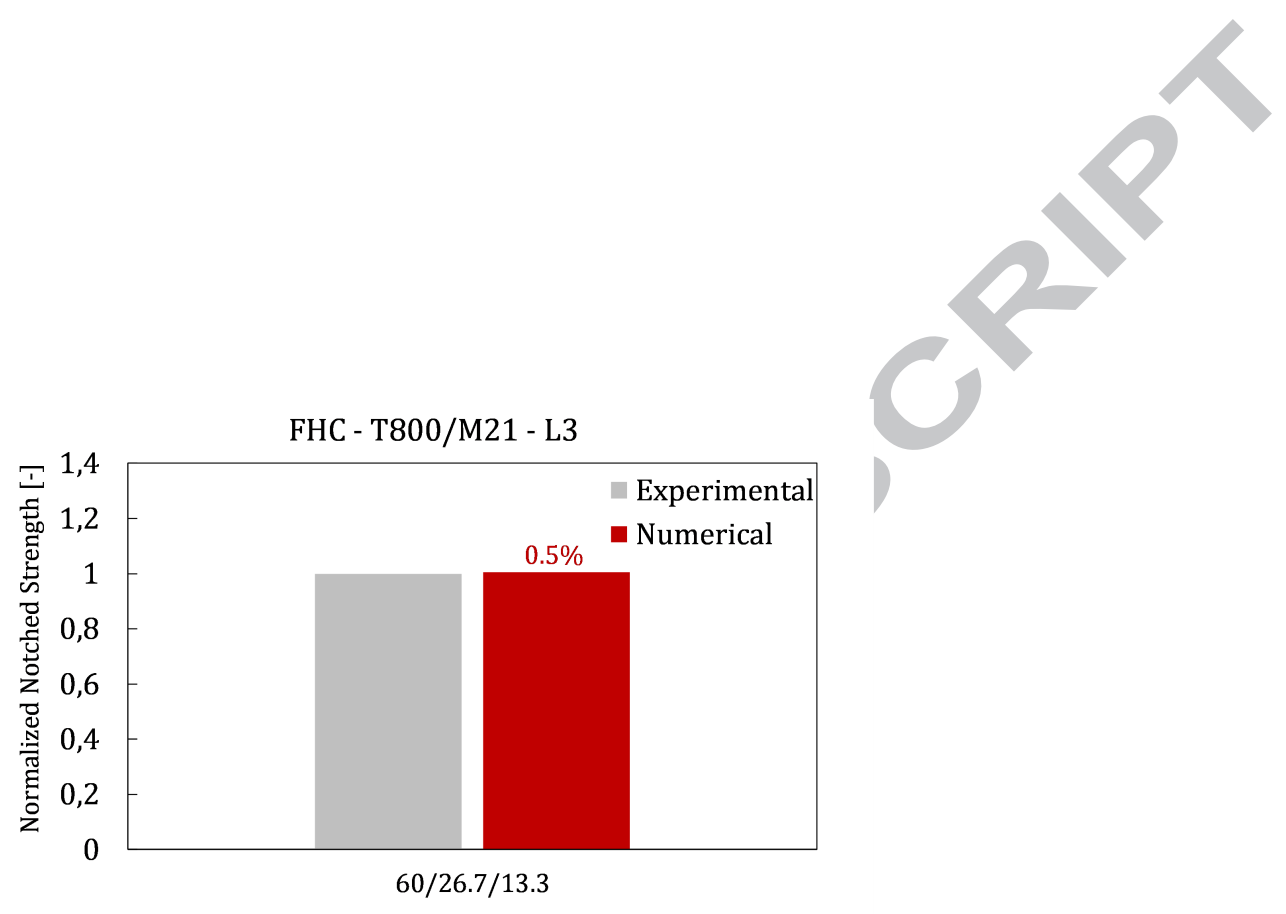

Figure 27: Comparison between the numerical and experimental results for the filled-hole compressive strength of one T800/M21 carbon/epoxy laminate. 


\section{Conclusions}

In this work, a methodology to simulate composite laminates at the coupon level based on modifications implemented in the continuum damage model proposed by Maimí et al. [16-18] and in the cohesive zone models based on the work of Turon et al. [22] and Alfano et al. [23] was proposed. The continuum damage model proposed by Maimí et al. [16-18] was enriched with a bilinear softening law for longitudinal compression more suitable to represent kinking failure, based on the experimental findings by Moran et al. [28]. Additionally, a damage activation function for longitudinal compression that accounts for the effect of though-thickness stresses based on the 3D failure criteria proposed by Camanho et al. [30] and engineering solutions to account for the effect of pressure on the longitudinal compression and in-plane shear fracture toughness were proposed. A frictional cohesive model proposed by the authors [36] was used in this work to more accurately represent delamination propagation and load carrying capability in test cases where the effect of through-thickness pressure cannot be neglected.

The methodology was thoroughly validated for various material systems and coupons with increasing level of complexity: from unnotched tension and compression, open-hole tension and compression and filled-hole compression of both soft and hard laminates. A good agreement was found between the predictions and the experimental ultimate strengths for all the test cases, , oftentimes within standard error of the tests, with maximum relative error of $13 \%$.

It is worth noting that the models developed follow the requirements typically used by the aeronautical industry, in terms of element size and mesh structure. Additionally, all the predictions were obtained using a common set of material properties and material models. These facts indicate that the work presented here is a step towards the simulation of failure of composite structures using a standard modelling strategy. Hence, this work serves as basis for modelling more complex geometries and can potentially be used for the generation of statistically-based design allowables for the most simple test cases when allied with powerful statistical tools.

\section{Data Availability}

The raw/processed data required to reproduce these findings cannot be shared at this time as the data also forms part of an ongoing study. 


\section{Acknowledgements}

This work was carried out within the project "ComDaMod - Composite Damage Modelling Improvements". The authors gratefully acknowledge the support provided by Airbus.

The first author acknowledges the support of the Portuguese Government's Fundação para a Ciência e Tecnologia, under the Grant SFRH/BD/115859/2016.

The third and fifth authors would like to thank the national support provided by FCT Fundação para a Ciência e Tecnologia through National Funds in the scope of project MITPTB/PFM/0005/2013. 


\section{Appendix A. Material properties and their determination}

The ply and interface properties required to populate the model proposed and suggested methods for their determination are provided in tables A.6 and A.7. Note that some properties, despite representing physical phenomena, are particularly hard to determine experimentally. To clarify punctual assumptions done in this work, the estimation of some of the material parameters is highlighter in this section.

Even though solutions to determine the cohesive laws for longitudinal tension and compression have been proposed throughout the years [75-79], they are particularly challenging to determine experimentally and there is up to date, no standard procedure to do so. In this work, the inflection points for the softening laws for longitudinal tension and compression $\left(f_{X_{T}}, f_{G T}\right.$ and $f_{X_{C}}$ ) which represent fibre bridging and crushing, respectively, were inversely identified using an open-hole or filled-hole simulation, since there was no experimental data available.

Similarly, the biaxial tensile and compressive strengths $\left(Y_{B T}\right.$ and $\left.Y_{B C}\right)$ are also impractical to determine, since the specimens are generally expensive to manufacture and the required complicated test rigs. A summary of test methods for composites under multiaxial and out-of-plane loading conditions is given in Ref. [80]. Micromechanical models can also be used to numerically determine the material response under multiaxial stress states [81, 82]. $Y_{B T}$ and $Y_{B C}$ were only available for IM7/8552 $[19,30]$ and were assumed from the remaining material systems by considering that the ratio $Y_{B T} / Y_{T}$ and $Y_{B C} / Y_{C}$ is constant and equal to the ratios available for the IM7/8552 material system.

The parameter, $f_{f x c}$, is a frictional parameter that represents the strengthening effect of pressure on the longitudinal compressive behaviour of the ply. The concept was first introduced here and therefore, no procedure was defined to determine it. For this reason, in this work, the parameters was inversely identified from an open-hole or filled-hole simulation, depending on the material system. 
Table A.6: Intralaminar material parameters and suggested method for their determination.

\begin{tabular}{|c|c|c|}
\hline & Material parameter & Methodology \\
\hline & Ply Elastic Properties & \\
\hline$E_{1}$ & Young's modulus for longitudinal tension & ASTM D3039 [83] \\
\hline$E_{1 c}$ & Young's modulus for longitudinal compression & Ref. [84] \\
\hline$E_{2}$ & Young's modulus for transverse tension & ASTM D3039 [83] \\
\hline$G_{12}$ & In-plane shear modulus & ASTM D3518 [85] \\
\hline \multirow[t]{2}{*}{$\nu_{12}$} & Major Poisson's coefficient & ASTM D3039 [83] \\
\hline & Ply strengths & \\
\hline$X_{T}$ & Longitudinal tensile strength & ASTM D3039 [83] \\
\hline$f_{X T}$ & $f_{X_{T}} X_{T}$ is the longitudinal tensile stress at inflection point & Note $(1)$ \\
\hline$X_{C}$ & Longitudinal compressive strength & Ref. [84] \\
\hline$f_{X C}$ & $f_{X_{C}} X_{C}$ is the longitudinal compression stress at inflection point & Note $(1)$ \\
\hline$Y_{T}$ & Transverse tensile strength $(2)$ & ASTM D3039 [83] \\
\hline$Y_{C}$ & Transverse compressive strength (2) & Ref. [86] ( \\
\hline$Y_{B T}$ & Biaxial transverse tensile strength & Note $(1)$ \\
\hline$Y_{B C}$ & Biaxial transverse compressive strength & Note (1) \\
\hline$S_{L}$ & In-plane shear strength $(2)$ & ASTM D3518 [85] \\
\hline$S_{L P}$ & Shear stress that activates plastic flow & Note (3) \\
\hline \multirow[t]{2}{*}{$K_{P}$} & Shear incremental stiffness under plastic flow & Note (3) \\
\hline & Fracture Toughness & $>$ \\
\hline $\mathcal{G}_{1+}$ & Fracture toughness for long. tension & Ref. [87] \\
\hline$f_{G T}$ & Portion of $G_{X T}$ dissipated up to the inflection point & Note (1) \\
\hline $\mathcal{G}_{1-}$ & Fracture toughness for longitudinal compression & Ref. $[64]$ \\
\hline $\mathcal{G}_{2+}$ & Mode I fracture toughness for transverse tension & ASTM D5528 [88] \\
\hline $\mathcal{G}_{2-}$ & Mode I fracture toughness for transverse compression & Calculated (4) \\
\hline \multirow[t]{2}{*}{$\mathcal{G}_{6}$} & Mode II fracture toughness & ASTM D7905 [89] \\
\hline & Geometrical & \\
\hline$t$ & Element thickness & Ply thickness \\
\hline \multirow[t]{2}{*}{$\alpha_{0}$} & Fracture angle of the UD ply subjected to uniaxial transverse comp. & $\approx 53^{\circ}[90]$ \\
\hline & Friction & \\
\hline$f_{f x c}$ & Internal frictional parameter under long. compression & Note $(1)$ \\
\hline$\eta_{G}$ & Internal frictional parameter under in-plane shear & Ref. [36] \\
\hline
\end{tabular}

(1) No standard methodology to determine this material parameter is available. The parameter is assumed or inversely identified.

(2) The references given provide methodologies to determine the UD strengths of the ply. The in-situ properties should be calculated in function of the ply thickness and the position in the laminate proposed in Appendix B

(3) Best fitting from the in-plane shear stress-strain curve of the ply

(4) $\mathcal{G}_{2-}=\mathcal{G}_{6} / \cos \left(\alpha_{0}\right)$ 


\section{ACCEPTED MANUSCRIPT}

Table A.7: Interlaminar material parameters and suggested method for their determination.

\begin{tabular}{|c|c|c|}
\hline & Material parameter & Methodology \\
\hline \multicolumn{3}{|c|}{ Penalty Stiffness } \\
\hline K & Penalty stiffness & Recommended value: $10^{6} \mathrm{~N} / \mathrm{mm}^{3}[65]$ \\
\hline \multicolumn{3}{|c|}{ Strengths } \\
\hline$\tau_{N}$ & Strength under pure mode I & ASTM D3039 [83] \\
\hline$\tau_{s h}$ & Strength under pure mode II & ASTM D3518 [85] \\
\hline \multicolumn{3}{|c|}{ Fracture Toughness } \\
\hline $\mathcal{G}_{I c}$ & Mode I fracture toughness & ASTM D3039 [83] \\
\hline $\mathcal{G}_{I I c}$ & Mode II fracture toughness & ASTM D7905 [89] \\
\hline$\eta$ & Mixed-mode interaction parameter & ASTM D6671 [91] \\
\hline \multicolumn{3}{|c|}{ Friction } \\
\hline$\mu$ & Friction coefficient & Note (1) \\
\hline
\end{tabular}

(1) The frictional parameter can be inversely identified following Ref. [36]

\section{Appendix B. Derivation of the in-situ properties}

Appendix B.1. Transverse tensile and in-situ shear strengths

Camanho et al. [48] considered three ply configurations to calculate the transverse tensile and in-plane shear strengths: thick, thin inner and thin outer plies.

Appendix B.1.1. Thick embedded plies

In a thick ply embedded in a multidirectional laminate, a slit crack such as the one shown in Fig. B.1 will propagate firstly in the transverse direction $(\mathrm{T})$, and therefore the mode $\mathrm{I}$ and mode II energy release rates read:

$$
\begin{aligned}
& \mathcal{G}_{I}(T)=\frac{\pi a_{0}}{2} \Lambda_{22}^{o} \sigma_{22}^{2} \\
& \mathcal{G}_{I I}(T)=\frac{\pi a_{0}}{2} \chi\left(\gamma_{12}\right)
\end{aligned}
$$

where $2 a_{0}$ is the slit crack length along the thickness, $\chi(\gamma)$ is given by:

$$
\chi\left(\gamma_{12}\right)=2 \int_{0}^{\gamma_{12}} \sigma_{12} d \gamma_{12}
$$

and $\Lambda_{22}^{o}$ is given by [92]:

$$
\Lambda_{22}^{o}=2\left(\frac{1}{E_{2}}-\frac{\nu_{12}^{2}}{E_{1}}\right)
$$




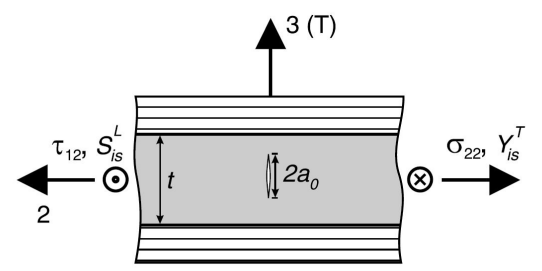

Figure B.1: Thick embedded ply [48]

Dvorak and Laws [92] proposed that the transverse tensile in-situ strength can be obtained by solving equation B.1 for $Y_{T}^{i s}$, yielding

$$
Y_{T}^{i s}=\sqrt{\frac{2 \mathcal{G}_{I c}(T)}{\pi a_{0} \Lambda_{22}^{0}}}
$$

In the Continuum Damage model presented here and implemented in the ABAQUS user subroutine, the shear response of a given laminated composite is approximated by:

$$
\sigma_{12}= \begin{cases}G_{12} \gamma_{12} & , \gamma_{12} \leq S_{L P} / G_{12} \\ K_{1} \gamma_{12}+K_{2} & , \gamma_{12}>S_{L P} / G_{12}\end{cases}
$$

where $K_{1}=\frac{K p G_{12}}{1+K p}$ and $K_{2}=S_{L P}\left(1-\frac{K p}{1+K p}\right), G_{12}$ is in-plane shear modulus, $S_{L P}$ is the shear stress at which the plastic flow is activated and $K p$ is the shear incremental stiffness under plastic flow. Having defined $\sigma_{12}$, the mode II fracture toughness can be calculated replacing (B.6) in equation (B.2), yielding:

$$
\begin{gathered}
\mathcal{G}_{I I c}(T)=\pi a_{0}\left[\int_{0}^{\frac{S_{L P}}{G_{12}}} G_{12} \gamma_{12} d \gamma_{12}+\int_{\frac{S_{L P}}{G_{12}}}^{\gamma_{12}^{i s}}\left(K_{1} \gamma_{12}+K_{2}\right) d \gamma_{12}\right]= \\
=\pi a_{0}\left[\left(\gamma_{12}^{i s}\right)^{2} \frac{K_{1}}{2}+\gamma_{12}^{i s} K_{2}-\frac{S_{L P}^{2}}{2 G_{12}(1+K p)}\right]
\end{gathered}
$$

Dvorak and Laws [92] also proposed that the a unidirectional laminate can be considered a special case of a thick ply with unconstrained outer surfaces and, therefore, the in-situ strengths of a thick ply can be related to those of an unidirectional thick ply. Using the classical solutions for stress intensity factors of surface cracks in unidirectional laminates [93], the mode I and mode II components of fracture toughness can also be calculated as

$$
\mathcal{G}_{I c}(T)=1.12^{2} \pi a_{0} \Lambda_{22}^{0}\left(Y^{T}\right)^{2}
$$


and

$$
\mathcal{G}_{I I c}(T)=2 \pi a_{0}\left[\gamma_{L}^{2} \frac{K_{1}}{2}+\gamma_{L} K_{2}-\frac{S_{L P}^{2}}{2 G_{12}(1+K p)}\right]
$$

where $\gamma_{L}=\frac{S_{L}-K_{2}}{K_{1}}$.

Combining equations (B.5) and (B.8), the transverse tensile in-situ strength for a thick ply yields:

$$
Y_{T}^{i s}=1.12 \sqrt{2} Y_{T}
$$

Combining equations (B.7) and (B.9), the in-plane shear strength can be obtained solving the following equation for $\gamma_{12}^{i s}$ :

$$
\left(\gamma_{12}^{i s}\right)^{2} \frac{K_{1}}{2}+\gamma_{12}^{i s} K_{2}=\gamma_{L}^{2} K_{1}+2 \gamma_{L} K_{2}-\frac{S_{L P}^{2}}{2 G_{12}(1+K p)}
$$

Knowing $\gamma_{12}^{i s}$ the in-plane shear strength can be obtained solving the second member of equation (B.6) for $\sigma_{12}$ :

$$
S_{L}^{i s}=\sqrt{2 S_{L}^{2}-S_{L P} K_{2}}
$$

\section{Appendix B.1.2. Thin embedded plies}

In thin plies embedded in a multidirectional laminate, a slit crack such as the one shown in Fig. B.2 will propagate in the longitudinal direction (L) since it already extended through the ply thickness and, therefore, the mode I and mode II energy release rate read [92]:

$$
\begin{aligned}
& \mathcal{G}_{\text {Ic }}(L)=\frac{\pi t}{8} \Lambda_{22}^{o} \sigma_{22}^{2} \\
& \mathcal{G}_{I I c}(L)=\frac{\pi t}{8} \chi\left(\gamma_{12}\right)
\end{aligned}
$$

The transverse tensile in-situ strength can be obtained by solving equation B.13 for $Y_{T}^{i s}$ yielding

$$
Y_{T}^{i s}=\sqrt{\frac{8 \mathcal{G}_{I c}}{\pi t \Lambda_{22}^{0}}}
$$

Replacing equation (B.3) in equation (B.14) yields

$$
\mathcal{G}_{I I c}=\frac{\pi t}{4}\left[\left(\gamma_{12}^{i s}\right)^{2} \frac{K_{1}}{2}+\gamma_{12}^{i s} K_{2}-\frac{S_{L P}^{2}}{2 G_{12}(1+K p)}\right]
$$




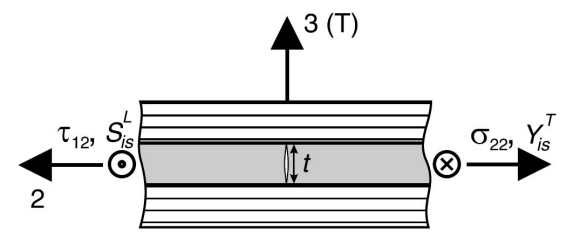

Figure B.2: Thin embedded ply [48]

which can be solved for $\gamma_{12}^{i s}$. Knowing $\gamma_{12}^{i s}$ the in-plane shear strength can be obtained solving the second member of equation B.6 for $\sigma_{12}$ :

$$
S_{L}^{i s}=\sqrt{\frac{8 \mathcal{G}_{I I c} K_{1}}{\pi t}+S_{L P} K_{2}}
$$

Appendix B.1.3. Thin outer plies

A thin outer ply is a special case of the thin ply for which the energy release rate is larger because the slit crack is closer to the surface of the laminate (Fig. B.3). The mode I and mode II energy release rate read:

$$
\begin{gathered}
\mathcal{G}_{I c}=1.22^{2} \frac{\pi t}{4} \Lambda_{22}^{o} \sigma_{22}^{2} \\
\mathcal{G}_{I I c}=\frac{\pi t}{4} \chi\left(\gamma_{12}\right)
\end{gathered}
$$

The transverse tensile in-situ strength can be obtained by solving equation B.18 for $Y_{T}^{i s}$ yielding

$$
Y_{T}^{i s}=1.78 \sqrt{\frac{\mathcal{G}_{I c}}{\pi t \Lambda_{22}^{0}}}
$$

Replacing equation (B.3) in (B.19), yields:

$$
\mathcal{G}_{I I c}=\frac{\pi t}{2}\left(\left(\gamma_{12}^{i s}\right)^{2} \frac{K_{1}}{2}+\gamma_{12}^{i s} K_{2}-\frac{S_{L P}^{2}}{2 G_{12}(1+K p)}\right)
$$

which can be solved for the $\gamma_{12}^{i s}$. Knowing $\gamma_{12}^{i s}$ the in-plane shear strength can be obtained solving the second member of equation B.6 for $\sigma_{12}$ :

$$
S_{L}^{i s}=\sqrt{\frac{4 \mathcal{G}_{I I c} K_{1}}{\pi t}+S_{L P} K_{2}}
$$




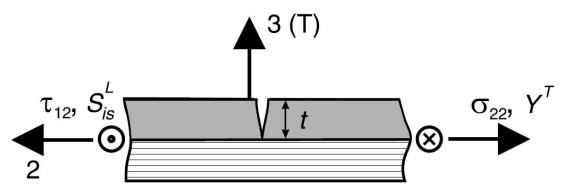

Figure B.3: Thin outer ply [48]

Appendix B.2. Transverse compressive strength

The in-situ transverse compressive stress $Y_{C}^{i s}$ is calculated imposing that the slope in the $\sigma_{22}-\sigma_{12}$ failure envelope when $\sigma_{22}=0, \eta_{L}$, is equal to the slope of the envelope obtained with the in-situ properties (see Fig. B.4). To maintain consistency between the assumptions made to derive the in-situ strengths and the assumed behavior of the material, the criterion used in both cases is the LaRC03-04 failure criterion [27]. The coefficient of longitudinal influence $\eta_{L}$ can be determined experimentally but in the absence of biaxial test data, it can be estimated as $[27,90]$

$$
\eta_{L}=\frac{-S_{L}^{U D} \cos \left(2 \alpha_{0}\right)}{Y_{C}^{U D} \cos ^{2}\left(\alpha_{0}\right)}
$$

and therefore, the in-situ transverse compressive strength $Y_{C}^{i s}$ can be estimated as

$$
\eta_{L}=\eta_{L, i s} \Leftrightarrow Y_{C}^{i s}=\frac{S_{L}^{i s} Y_{C}^{U D}}{S_{L}^{U D}}
$$

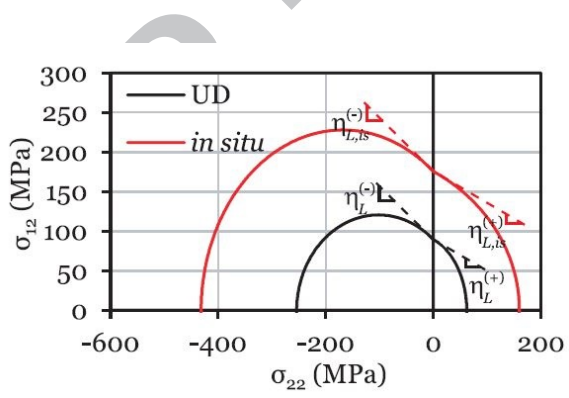

Figure B.4: $\sigma_{22}-\sigma_{12}$ failure envelope [30]

\section{Appendix B.3. General expression for the in-situ strengths}

The general expression for the in-situ strengths are presented in this section.

\section{For an embedded ply:}


- the in-situ transverse tensile strength is the maximum between the transverse tensile strength of a thin embedded ply and a thick embedded ply, i.e.:

$$
Y_{T}^{i s}=\max \left\{\sqrt{\frac{8 \mathcal{G}_{I c}}{\pi t \Lambda_{22}^{o}}} \quad, \quad 1.12 \sqrt{2} Y_{T}^{U D}\right\}
$$

- the in-situ in-plane shear strength is the maximum between the in-plane shear strength of a thin embedded ply and a thick embedded ply, i.e.:

$$
S_{L}^{i s}=\max \left\{\sqrt{\frac{8 \mathcal{G}_{I I c} K_{1}}{\pi t}+S_{L P} K_{2}} \quad, \quad \sqrt{2 S_{L}^{2}-S_{L P} K_{2}}\right\}
$$

- the $i n$-situ transverse compressive strength $Y_{C}^{i s}$ is given by:

$$
Y_{C}^{i s}=\frac{S_{L}^{i s} Y_{C}^{U D}}{S_{L}^{U D}}
$$

\section{For an outer ply:}

- the $i n$-situ transverse tensile strength is the maximum between:

$$
Y_{T}^{i s}=\max \left\{1.78 \sqrt{\frac{\mathcal{G}_{I c}}{\pi t \Lambda_{22}^{o}}} \quad, \quad Y_{T}^{U D}\right\}
$$

- The in-situ in-plane shear strength is the maximum between the in-plane shear strength of a thin outer ply and an UD ply, i.e.:

$$
S_{L}^{s s}=\max \left\{\sqrt{\frac{4 \mathcal{G}_{I I c} K_{1}}{\pi t}+S_{L P} K_{2}} \quad, \quad S_{L}^{U D}\right\}
$$

- the $i n$-situ transverse compressive strength $Y_{C}^{i s}$ is given by:

$$
Y_{C}^{i s}=\frac{S_{L}^{i s} Y_{C}^{U D}}{S_{L}^{U D}}
$$

\section{Appendix C. Engineering solutions used in the modelling strategies S2 and S3}

Cohesive finite elements require very fine meshes: the fracture process zone should include at least three cohesive elements so that delamination is accurately simulated. Turon et al. [51] 
proposed an engineering solution to avoid the use of such refined meshes that consists of lowering the cohesive strengths whilst keeping the fracture toughness constant to enlarge the cohesive zone and to allow a better representation of the softening behaviour at the vicinity of the crack tip. Following Refs. [51, 52], the cohesive properties should therefore, be determined as follows:

1. Take the penalty stiffness, $K$, equal to $10^{6} \mathrm{~N} / \mathrm{mm}^{3}[65]$

2. Determine the transverse tensile strength $Y_{T}^{U D}$ (ASTM D3039 [83])

3. Determine the mode I fracture toughness $\mathcal{G}_{\text {Ic }}(\mathrm{ASTM}$ D5528 [88])

4. Determine the mode II fracture toughness $\mathcal{G}_{I I c}(\mathrm{ASTM}$ D7905 [89])

5. Select the element size in the direction of crack propagation, $l_{e}[51]$

6. Select the number of elements in the cohesive zone, $N_{e}$, which should be at least 3 [51]

7. Calculate the strength in pure mode I as: $\bar{\tau}_{N}=\sqrt{\frac{9 \pi E_{2} \mathcal{G}_{I c}}{32 N_{e} l_{e}}}[51]$

8. Calculate the effective strength in pure mode I as [51]

$$
\tau_{N}=\min \left\{Y_{T}^{U D}, \bar{\tau}_{N}\right\}
$$

It was shown that through-thickness compression increases the interlaminar shear strength of laminates and delays delamination [34-36]. Cui et al. [37] suggests that this strengthening effect is a result of an increase on mode II fracture toughness under through-thickness compression that can be expressed as:

$$
\mathcal{G}_{I I c}^{e f}=\mathcal{G}_{I I c}\left(1-\eta_{G}\left\langle-\sigma_{33}\right\rangle\right)
$$

where $G_{I I c}$ is the mode II fracture toughness, $\eta_{G}$ a material dependent empirically derived enhancement factor, $\sigma_{33}$ is the through-thickness stress and $\langle x\rangle$ is the Mccaulay operator. [37, 38]. In situation where the applied pressure is fairly constant (e.g. in bolt bearing and filled-hole compression tests), equation C.2 can be used to artificially account for the strengthening effect on the interfaces caused by friction under shear.

\section{References}

[1] Handbook-MIL-HDBK M. 17-3f: Composite materials handbook, volume 3-polymer matrix composites materials usage, design, and analysis. US Department of Defense 2002;. 
[2] Tsai SW, Melo JDD. A unit circle failure criterion for carbon fiber reinforced polymer composites. Composites Science and Technology 2016;123:71-8.

[3] Tsai SW, Melo JDD. Composite Materials Design and Testing - Unlocking mystery with invariants. Stanford: Composites Design Group, Department of Aeronautics and Astronautics, Stanford University; 2015.

[4] J. M. W, Nuismer RJ. Stress fracture criteria for laminated composites containing stress concentrations. Journal of Composite Materials 1974;(8):253-65.

[5] Waddoups M. E. EJR, Kaminski BE. Macroscopic fracture mechanics of advanced composite materials. Journal of Composite Materials 1971;(5):446-54.

[6] Camanho PP, Erçin GH, Catalanotti G, Mahdi S, Linde P. A finite fracture mechanics model for the prediction of the open-hole strength of composite laminates. Composites Part A: Applied Science and Manufacturing 2012;43(8):1219-25.

[7] Camanho PP, Lambert M. A design methodology for mechanically fastened joints in laminated composite materials. Compos Sci Technol 2006;66:3004-20.

[8] Furtado C, Arteiro A, Bessa MA, Wardle BL, Camanho PP. Prediction of size effects in open-hole laminates using only the Young's modulus, the strength, and the R-curve of the $0^{\circ}$ ply. Composites Part A: Applied Science and Manufacturing 2017;101:306-17.

[9] Tay T, Tan SHN, Tan VBC, Gosse JH. Damage progression by the element-failure method (efm) and strain invariant failure theory (sift). Composites Science and Technology 2005;65(6):935-44.

[10] Abisset E, Daghia F, Ladevèze P. On the validation of a damage mesomodel for laminated composites by means of open-hole tensile tests on quasi-isotropic laminates. Composites Part A: Applied Science and Manufacturing 2011;42(10):1515-24.

[11] Iarve V, Gurvich MR, Mollenhauer DH, Rose CA, Dávila CG. Mesh-independent matrix cracking and delamination modeling in laminated composites. International journal for numerical methods in engineering 2011;88(8):749-73.

[12] Van der Meer FP, Oliver C, Sluys L. Computational analysis of progressive failure in a notched laminate including shear nonlinearity and fiber failure. Composites Science and Technology 2010;70(4):692-700. 
[13] Ling D, Yang Q, Cox B. An augmented finite element method for modeling arbitrary discontinuities in composite materials. International Journal of Fracture 2009;156(1):53-73.

[14] Wisnom MR. Modelling discrete failures in composites with interface elements. Composites Part A: Applied Science and Manufacturing 2010;41(7):795-805.

[15] Schuecker C, Pettermann HE. A continuum damage model for fiber reinforced laminates based on ply failure mechanisms. Composite structures 2006;76(1):162-73.

[16] Maimí P, Camanho PP, Mayugo J, Dávila CG. A continuum damage model for composite laminates: Part II Computational implementation and validation. Mechanics of Materials 2007;39(10):909-19.

[17] Maimí P, Camanho PP, Mayugo J, Dávila CG. A continuum damage model for composite laminates: Part I Constitutive model. Mechanics of Materials 2007;39(10):897 - 908.

[18] Maimí P. Modelización constitutiva y computacional del daño y la fractura de materiales compuestos. Ph.D. thesis; Universitat de Girona, Catalunya, Spain; 2007.

[19] Vogler M, Rolfes R, Camanho PP. Modeling the inelastic deformation and fracture of polymer composites Part I: Plasticity model. Mechanics of Materials 2013;59:50-64.

[20] Camanho PP, Bessa MA, Catalanotti G, Vogler M, Rolfes R. Modeling the inelastic deformation and fracture of polymer composites-Part II: smeared crack model. Mechanics of Materials 2013;59:36-49.

[21] Reinoso J, Arteiro A, Paggi M, Camanho P. Strength prediction of notched thin ply laminates using finite fracture mechanics and the phase field approach. Composites Science and Technology 2017;150:205-16.

[22] Turon A, González E, Sarrado C, Guillamet G, Maimí P. Accurate simulation of delamination under mixed-mode loading using a cohesive model with a mode-dependent penalty stiffness. Composite Structures 2018;184:506 -11.

[23] Alfano G, Sacco E. Combining interface damage and friction in a cohesive-zone model. International Journal for Numerical Methods in Engineering 2006;68(5):542-82.

[24] González EV, Maimí P, Camanho PP, Turon A, Mayugo JA. Simulation of drop-weight impact and compression after impact tests on composite laminates. Composite Structures 2012;94(11):3364 -78. 
[25] Soto A, González E, Maimí P, de la Escalera FM, de Aja JRS, Alvarez E. Low velocity impact and compression after impact simulation of thin ply laminates. Composites Part A: Applied Science and Manufacturing 2018;109:413 -27.

[26] Soto A, González EV, Maimí P, Mayugo JA, Pasquali PR, Camanho PP. A methodology to simulate low velocity impact and compression after impact in large composite stiffened panels. Composite Structures 2018;204:223-38.

[27] Dávila CG, Camanho PP, Rose CA. Failure criteria for FRP laminates. Journal of Composite materials 2005;39(4):323-45.

[28] Moran PM, Liu XH, Shih CF. Kink band formation and bandbroadening in fiber composites under compressive loading. Acta Metallurgica et Materialia 1995;43(8):2943-58.

[29] Bažant ZP, Oh BH. Crack band theory for fracture of concrete. Mater Struct 1983;16(93):155-77.

[30] Camanho PP, Arteiro A, Melro AR, Catalanotti G, Vogler M. Three-dimensional invariantbased failure criteria for fibre-reinforced composites. International Journal of Solids and Structures 2015;55:92-107.

[31] Weaver CW, Williams JG. Deformation of a carbon-epoxy composite under hydrostatic pressure. Journal of Materials Science 1975;10(8):1323-33.

[32] Parry TV, Wronski AS. Kinking and compressive failure in uniaxially aligned carbon fibre composite tested under superposed hydrostatic pressure. Journal of Materials Science 1982;17(3):893-900.

[33] Rabinowitz S, Ward IM, Parry JSC. The effect of hydrostatic pressure on the shear yield behaviour of polymers. Journal of Materials Science 1970;5(1):29-39.

[34] Cartié D, Davies P, Peleau M, Partridge IK. The influence of hydrostatic pressure on the interlaminar fracture toughness of carbon/epoxy composites. Composites Part B: Engineering 2006;37(4):292-300.

[35] Bing Q, Sun CT. Effect of compressive transverse normal stress on mode ii fracture toughness in polymeric composites. International Journal of Fracture 2007;145(2):89-97. 
[36] Catalanotti G, Furtado C, Scalici T, Pitarresi G, der Meer FPV, Camanho P. The effect of through-thickness compressive stress on mode II interlaminar fracture toughness. Composite Structures 2017;182:153-63.

[37] Cui W, Wisnom MR, Jones M. Effect of through thickness tensile and compressive stresses on delamination propagation fracture energy. Journal of Composites Technology and Research 1994;16(4):329-35. Cited By 13.

[38] Li X, Hallett SR, Wisnom MR. Predicting the effect of through-thickness compressive stress on delamination using interface elements. Composites Part A: Applied Science and Manufacturing 2008;39(2):218 -30.

[39] Parvizi A, Garrett KW, Bailey JE. Constrained cracking in glass fibre-reinforced epoxy cross-ply laminates. Journal of Materials Science 1978;13(1):195-201.

[40] Chang F, Chen M. The in situ ply shear strength distributions in graphite/epoxy laminated composites. Journal of Composite Materials 1987;21(8):708-33.

[41] Garrett KW, Bailey JE. Multiple transverse fracture in 90 cross-ply laminates of a glass fibre-reinforced polyester. Journal of materials science 1977;12(1):157-68.

[42] Parvizi A, Bailey J. On multiple transverse cracking in glass fibre epoxy cross-ply laminates. Journal of Materials Science 1978;13(10):2131-6.

[43] Flaggs DL, Kural MH. Experimental determination of the in situ transverse lamina strength in graphite/epoxy laminates. Journal of composite materials 1982;16(2):103-16.

[44] Boniface L, Smith PA, Bader MG, Rezaifard AH. Transverse ply cracking in cross-ply CFRP laminatesinitiation or propagation controlled? Journal of composite materials 1997;31(11):1080-112.

[45] Sebaey TA, Costa J, Maimí P, Batista Y, Blanco N, Mayugo JA. Measurement of the in situ transverse tensile strength of composite plies by means of the real time monitoring of microcracking. Composites Part B: Engineering 2014;65:40-6.

[46] Arteiro A, Catalanotti G, Melro AR, Linde P, Camanho PP. Micro-mechanical analysis of the in situ effect in polymer composite laminates. Composite Structures 2014;116:827-40. 
[47] Arteiro A, Catalanotti G, Melro A, Linde P, Camanho PP. Micro-mechanical analysis of the effect of ply thickness on the transverse compressive strength of polymer composites. Composites Part A: Applied Science and Manufacturing 2015;79:127-37.

[48] Camanho PP, Dávila CG, Pinho ST, Iannucci L, Robinson P. Prediction of in situ strengths and matrix cracking in composites under transverse tension and in-plane shear. Composites Part A: Applied Science and Manufacturing 2006;37(2):165-76.

[49] Catalanotti G. Prediction of in situ strengths in composites: Some considerations. Composite Structures 2019;207:889-93.

[50] Rose CA, Dávila CG, Leone FA. Analysis Methods for Progressive Damage of Composite Structures. Tech. Rep. July; NASA Langley Research Center; Hampton, VA, United States; 2013.

[51] Turon A, Dávila CG, Camanho PP, Costa J. An engineering solution for mesh size effects in the simulation of delamination using cohesive zone models. Engineering Fracture Mechanics 2007;74(10):1665-82.

[52] Turon A, Camanho PP, Costa J, Renart J. Accurate simulation of delamination growth under mixed-mode loading using cohesive elements: Definition of interlaminar strengths and elastic stiffness. Composite Structures 2010;92(8):1857 -64.

[53] Mi Y, Crisfield MA, Davies GAO, Hellweg HB. Progressive delamination using interface elements. Journal of composite materials 1998;32(14):1246-72.

[54] Turon A, Camanho PP, Costa J, Dávila C. An interface damage model for the simulation of delamination under variable-mode ratio in composite materials. NASA TP Technical Reports 2004;

[55] González EV, Maimí P, Turon A, Camanho PP, Renart J. Simulation of delamination by means of cohesive elements using an explicit finite element code. Computers, Materials \& Continua 2009;9(1):51-92.

[56] Benzeggagh ML, Kenane M. Measurement of mixed-mode delamination fracture toughness of unidirectional glass/epoxy composites with mixed-mode bending apparatus. Composites science and technology 1996;56(4):439-49. 
[57] Camanho PP, Maimí P, Dávila CG. Prediction of size effects in notched laminates using continuum damage mechanics. Compos Sci Technol 2007;67:2715-27.

[58] Bessa M. Meso-mechanical model of the structural integrity of advanced composite laminates. Master's thesis; Faculdade de Engenharia, Universidade do Porto; Porto; 2010.

[59] Giddings PF, Bowen CR, Salo AI, Kim HA, Ive A. Bistable composite laminates: Effects of laminate composition on cured shape and response to thermal load. Composite Structures 2010;92(9):2220 -5.

[60] Huchette C. Sur la complémentarité des approches expérimentales et numériques pour la modélisation des mécanismes d'endommagement des composites stratifiés. Ph.D. thesis; Université Paris 6; Paris; 2005. In French.

[61] Erçin GH. Stress gradient effects in laminated composites. Ph.D. thesis; Faculdade de Engenharia, Universidade do Porto; Porto; 2013.

[62] Marn L, Trias D, Badall P, Rus G, Mayugo J. Optimization of composite stiffened panels under mechanical and hygrothermal loads using neural networks and genetic algorithms. Composite Structures 2012;94(11):3321 -6.

[63] Airbus. Internal communication. Tech. Rep.; 2015.

[64] Catalanotti G, Xavier J, Camanho PP. Measurement of the compressive crack resistance curve of composites using the size effect law. Composites Part A: Applied Science and Manufacturing 2014;56:300-7.

[65] Camanho PP, Dávila CG, de Moura MF. Numerical simulation of mixed-mode progressive delamination in composite materials. Composite Materials 2003;37(16).

[66] C. M. L. T. Fracture of advanced composite materials: experimental basis for a constitutive model. Tech. Rep.; University of Porto, Porto, Portugal; 2006.

[67] Lopes CS, Camanho PP, Gurdal Z, Maimí P, González EV. Low-velocity impact damage on dispersed stacking sequence laminates. Part II: Numerical simulations. Composites Science and Technology 2009;69(7):937 -47.

[68] Xu X, Wisnom MR, Mahadik Y, Hallett SR. An experimental investigation into size effects in quasi-isotropic carbon/epoxy laminates with sharp and blunt notches. Composites Science and Technology 2014;100:220-7. 
[69] Xu X, Wisnom MR, Mahadik Y, Hallett SR. Scaling of fracture response in over-height compact tension tests. Composites Part A: Applied Science and Manufacturing 2015;69:408.

[70] Erçin GH, Camanho PP, Xavier J, Catalanotti G, Mahdi S, Linde P. Size effects on the tensile and compressive failure of notched composite laminates. Composite Structures 2013;96:736-44.

[71] Furtado C, Arteiro A, Catalanotti G, Xavier J, Camanho PP. Selective ply-level hybridisation for improved notched response of composite laminates. Composite Structures 2016;145:1 -14 .

[72] Leone FA. Deformation gradient tensor decomposition for representing matrix cracks in fiber-reinforced materials. Composites Part A: Applied Science and Manufacturing 2015;76:334 -41.

[73] Falcó O, vila RL, Tijs B, Lopes CS. Modelling and simulation methodology for unidirectional composite laminates in a virtual test lab framework. Composite Structures 2018;190:137 -59.

[74] Dassault Systèmes . ABAQUS User's Manual. 2011.

[75] Cornelissen HAW, Hordijk DA, Reinhardt HW. Experimental determination of crack softening characteristics of normalweight and lightweight. Heron 1986;31:45.

[76] Hordijk DA. Fracture mechanics parameters of concrete from uniaxial tensile tests as influensed by specimen length, fracture of concrete and rock. Society Experimental Mechanics $1987 ;: 138-49$.

[77] Bergan A, Dávila C, Leone F, Awerbuch J, Tan T. A mode i cohesive law characterization procedure for through-the-thickness crack propagation in composite laminates. Composites Part B: Engineering 2016;94:338-49.

[78] Zobeiry N, Vaziri R, Poursartip A. Characterization of strain-softening behavior and failure mechanisms of composites under tension and compression. Composites Part A: Applied Science and Manufacturing 2015;68:29-41.

[79] Ortega A, Maimí P, González EV, Trias D. Characterization of the translaminar fracture cohesive law. Composites Part A: Applied Science and Manufacturing 2016;91:501-9. 
[80] Olsson R. A survey of test methods for multiaxial and out-of-plane strength of composite laminates. Composites Science and Technology 2011;71(6):773-83.

[81] Melro AR. Analytical and numerical modelling of damage and fracture of advanced composites. Ph.D. thesis; Universidade do Porto, Porto, Portugal; 2007.

[82] van der Meer FP. Micromechanical validation of a mesomodel for plasticity in composites. European Journal of Mechanics-A/Solids 2016;60:58-69.

[83] ASTM D 3039 D 3039M-14, . Standard Test Method for Tensile Properties of Polymer Matrix Composite Materials. West Conshohocken, PA: ASTM International; 2014, www.astm.org,.

[84] Koerber H, Camanho PP. High strain rate characterisation of unidirectional carbon-epoxy IM7-8552 in longitudinal compression. Composites Part A: Applied Science and Manufacturing 2011;42(5):462-70.

[85] ASTM D 3518 D 3518M-13, . Standard Test Method for In-Plane Shear Response of Polymer Matrix Composite Materials by Tensile Test of a \pm 45 Laminate. West Conshohocken, PA: ASTM International; 2013, www.astm.org,.

[86] Koerber H, Xavier J, Camanho PP. High strain rate characterisation of unidirectional carbon-epoxy IM7-8552 in transverse compression and in-plane shear using digital image correlation. Mechanics of Materials 2010;42(11):1004-19.

[87] Catalanotti G, Arteiro A, Hayati M, Camanho PP. Determination of the mode I crack resistance curve of polymer composites using the size-effect law. Engineering Fracture Mechanics 2014;118:49-65.

[88] ASTM D 5528, . Standard Test Method for Mode I Interlaminar Fracture Toughness of Unidirectional Fiber-Reinforced Polymer Matrix Composites. West Conshohocken, PA: ASTM International; 2013, www.astm.org,.

[89] ASTM D7905 D7905M, . Standard Test Method for Determination of the Mode II Interlaminar Fracture Toughness of Unidirectional Fiber-Reinforced Polymer Matrix Composites. West Conshohocken, PA: ASTM International; 2014, www.astm.org,.

[90] Puck A. Failure analysis of FRP laminates by means of physically based phenomenological models. Composites Science and Technology 1998;58(7):1045-67. 
[91] ASTM D 6671 D 6671M, . Standard Test Method for Mixed Mode I-Mode II Interlaminar Fracture Toughness of Unidirectional Fiber Reinforced Polymer Matrix Composites. West Conshohocken, PA: ASTM International; 2013, www.astm.org,.

[92] Dvorak GJ, Laws N. Analysis of progressive matrix cracking in composite laminates II. First ply failure. Journal of Composite Materials 1987;21(4):309-29.

[93] Tada H, Paris PC, Irwin GR. The Stress Analysis of Cracks Handbook. The American Society of Mechanical Engineers. New York 2000;. 